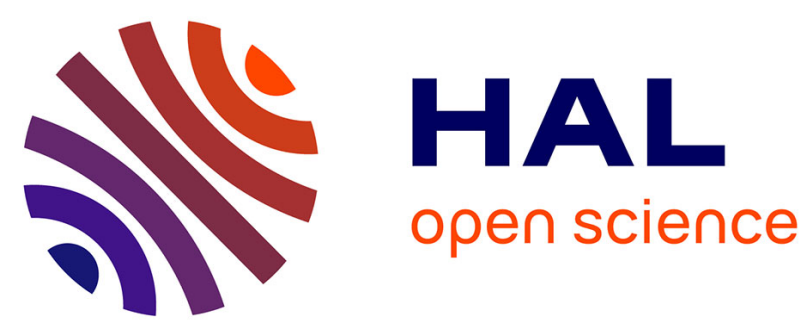

\title{
Chord length distributions measurements during crystallization and agglomeration of gas hydrate in a water-in-oil emulsion: Simulation and experimentation
}

Hung Le Ba, Ana Cameirão, Jean-Michel Herri, Myriam Darbouret, Jean-Louis Peytavi, Philippe Glénat

\section{To cite this version:}

Hung Le Ba, Ana Cameirão, Jean-Michel Herri, Myriam Darbouret, Jean-Louis Peytavi, et al.. Chord length distributions measurements during crystallization and agglomeration of gas hydrate in a waterin-oil emulsion: Simulation and experimentation. Chemical Engineering Science, 2010, 65 (3), pp.11851200. 10.1016/j.ces.2009.09.074 . hal-00461966

\section{HAL Id: hal-00461966 https://hal.science/hal-00461966}

Submitted on 8 Mar 2010

HAL is a multi-disciplinary open access archive for the deposit and dissemination of scientific research documents, whether they are published or not. The documents may come from teaching and research institutions in France or abroad, or from public or private research centers.
L'archive ouverte pluridisciplinaire HAL, est destinée au dépôt et à la diffusion de documents scientifiques de niveau recherche, publiés ou non, émanant des établissements d'enseignement et de recherche français ou étrangers, des laboratoires publics ou privés. 


\title{
Chord length distributions measurements during crystallization and agglomeration of gas hydrate in a water-in-oil emulsion: Simulation and experimentation
}

\author{
LE BA Hung(1), CAMEIRAO Ana(1) *, HERRI J ean-Michel(1), DARBOURET Myriam(2), \\ PEYTAVI J ean-Louis (3), GLENAT Philippe ${ }^{(3)}$
}

Ecole Nationale Supérieure des Mines de Saint Etienne, Centre SPIN - Département GENERIC ; LPMG-UMR CNRS 5148, 158 Cours Fauriel - 42023 Saint-Étienne Cedex 2, France

IFP Lyon, Fluid Mechanics Department, Rond-Point de l'Echangeur de Solaize, BP3, 69360 Solaize

TOTAL - CSTJF - Avenue Larribau, 64018 PAU Cedex - FRANCE

\begin{abstract}
:
The formation of gas hydrates from water-in-oil emulsion was investigated on two different flow loops: a laboratory scale flow loop (Archimede flow loop: $30 \mathrm{~m}$ long, and $1 \mathrm{~cm}$ diameter, St-Etienne School of Mines) and a pilot scale flow loop (Lyre flow loop: $150 \mathrm{~m} \mathrm{long}, 5 \mathrm{~cm}$ diameter, IFP Solaize). Both flow loops are equipped with a focused beam reflectance measurement (FBRM) probe for in situ particle size analysis. These FBRM probes were used to monitor chord length distribution (CLD) during the crystallization process of water-in-oil emulsions into gas hydrate slurries. When water droplets crystallize into hydrate particles, an agglomeration phenomenon is evidenced by pressure drop measurements. This agglomeration phenomenon is also detected by the FBRM probe and is highlighted by a sharp change in the mean chord length and a spread of the CLD to larger chord length. In order to better interpret the chord length distribution measurements, a modelling work has been made. This paper gives a description of the algorithm used for building $3 \mathrm{D}$ fractal aggregates and simulating CLD measurements on them. Aggregates are constructed from a monodisperse spherical particle. The influence of different parameters (fractal dimension, number of particles in the aggregate, diameter of primary particles) on the simulated CLD is also discussed. Some comparisons between experimental and simulated CLD are finally used to describe the physical properties of aggregates during an experiment.
\end{abstract}

Keywords:

Crystallization; Gas hydrates; Agglomeration; CLD (chord length distribution); FBRM (focused beam reflectance measurement)

\section{Introduction}

Gas hydrates are solid compounds made of gas molecules confined by water molecules, in conditions of high pressure and low temperature. In the context of offshore oil production lines which frequently operate under high pressure and low temperature, formation of gas hydrates can cause severe production disruptions. Once hydrates form in the pipeline, individual particles agglomerate together and form a plug in the pipeline preventing fluid flow (Sloan, 1998). These phenomena are linked to a viscosity increase due to particle agglomeration and the formation of aggregates that trap a volume of oil and therefore present an effective volume fraction higher than the real volume fraction of particles and droplets.

* Auteur à qui la correspondance devait être adressée : cameirao@emse.fr 
These aggregates can be described as fractal objects with a fractal dimension $D_{f}$ which characterizes the compactness of the object. The number of particles $N$ in a fractal aggregate can be expressed depending on the diameter of its constitutive particles $D_{p}$ and the apparent diameter $D_{A}$ of the aggregate as follows (Filippov et al., 2000):

$$
N \propto\left(\frac{D_{A}}{D_{P}}\right)^{D f}
$$

The more the aggregate is compact the closer is its effective volume fraction to the actual volume fraction of water droplets and hydrate particles. The ratios of these two quantities are linked to the ratio of the diameters of the aggregate and of the primary particles by the fractal dimension throw a power law (Camargo and Palermo, 2002):

$$
\frac{\Phi_{\text {eff }}}{\Phi} \propto\left(\frac{D_{A}}{D_{P}}\right)^{3-D f}
$$

Several studies have postulated that the existence of fractal aggregates could explain the fact that the viscosity of hydrate suspensions is higher that the classical model can predict, assuming a solid content directly equal to the initial water volume. In fact, as it was said just before, the existence of fractal agglomerates which immobilises liquid in their internal porosity is a way to justify that the effective solid content is higher than the sum of the volume of the individual solid particles.

Following (Mills, 1985) who postulated first that the existence of fractal aggregates could justify unusual viscosity, (Camargo and Palermo, 2002) have retained this hypothesis to model the consequences on viscosity of hydrate crystallization within an emulsion of water in an asphaltenic crude oil which exhibited natural anti-agglomeration properties.

The concepts of Camargo's model were re-used by (Fidel-Dufour et al. , 2006) to develop a kinetic model of hydrate crystallization. This model describes the crystallization process as a phenomenon limited by gas transfer in the oil phase due to consumption of gas dissolved in the oil in the neighbourhood of each water droplet. The agglomeration effects were once again attributed to collision between a water droplet and two other objects (either hydrate primary particle or hydrate aggregate). This water droplet was supposed to form a water bond between the two objects which lastly crystallized. So, at the end of the agglomeration, the model of (Camargo and Palermo, 2002), followed by (Turner et al., 2005) and (Fidel-Dufour et al., 2006) postulates that the aggregates are fractal aggregates formed of spherical particles whose sizes are the sizes of the initial emulsion.

The in situ FBRM probe is described as a robust tool as it is able to make measurements in opaque or dark mediums and in dense suspensions. That is why it raises a great interest in the field of petroleum studies. Moreover, a great advantage of the FBRM probe is that there is no need to sample and dilute the suspensions before making a measurement, thus allowing an on line, in situ follow-up. Therefore, this tool was used for different experimental studies to follow nucleation, growth and/or agglomeration (Richmond et al., 1998; Worlitschek, 2003). Moreover, in the case of hydrate crystallization, the use of an in situ probe allows to maintain the thermodynamic conditions (high pressure, low temperature). (Clarke and Bishnoi, 2004) and (Clarke and Bishnoi, 2005) recently published the monitoring of the FBRM probe in the case of $\mathrm{CO}_{2}$ hydrate crystallization in water. The hydrate particle nucleation was responsible for a steep increase of the number of chords detected per second. Then hydrate particles growth and agglomeration were successively evidenced with an increase of the number of large chord lengths detected per seconds, and consequently, of the mean chord length. (Turner et al., 2005) also used a Lasentec FBRM probe to study, the impact on the CLD of hydrate formation in crude oil under shear conditions. They evidenced that hydrate crystallization does 
not affect the size of primary particles so that the size of the initial water droplets in the emulsion determines the size of primary particles constituting an aggregate. (Panchard et al., 2007) also used a FBRM probe in order to evidence agglomeration effects due to the crystallization of an emulsion of water in crude oil into a hydrate suspension. Hydrate slurries were generated under shear condition in the pilot loop $(5 \mathrm{~cm}$ of internal diameter, $140 \mathrm{~m}$ of length). A methodology was used in order to distinguish between the effects of agglomeration on the apparent viscosity of the hydrate suspension.

Nevertheless the FBRM technique leaves many problems unsolved as it is well known that this probe does not provide an apparent PSD (particle size distribution) measurement but an apparent CLD (chord length distribution). Here, the term "apparent" refers to the fact that the measured size is dependent of the technology which is used (laser diffraction, turbidity, backscattering, visual microscopy for example).

So, using a FBRM probe, two questions arise. The first concerns the relation between the apparent CLD (the CLD that is measured by the probe) and the real one (the true CLD of the objects), but this question concerns any technique of size characterization. The second question concerns the relation between the real CLD and the real PSD. Then, comparing with other techniques, a third question arises which is the relation between the real PSD and the apparent PSD that is measured by other technique.

Concerning the first question, several authors have shown that FBRM measures a CLD beyond the size of the particles that have been characterised with another technique (laser diffraction in the case of (Heath et al., 2002) visual characterization in the case of (Greaves et al., 2008). In this paper (part 2.2, Figure 6) are given some elements going in the same way. Also, during this work experiments show that the intensity of the signal can be affected by the nature of the particles: a population of water droplets has not necessary the same CLD signature than a population of hydrate particles, a priori with the same size distribution. So, the issue of the interpretation of the apparent CLD in a real CLD is a question by itself which is not discussed in the paper.

This paper discusses in a first part the general item of the relation between a true CLD and a true PSD. Experimental results are discussed assuming that the apparent CLD is closed to the true one, with the reserves that have been made previously. But, the experimental results compared to the model are very encouraging.

The relationship between the true PSD and the true CLD has been the topic of many papers and discussions. The first work to calculate the CLD from PSD for 2-dimensional spherical particles is given using the probability apportioning method or Bayes' theorem (Langston, 2002; Langston and Jones, 2001; Simmons et al., 1999; Wynn, 2003; Li and Wilkinson, 2005). Then the analytical solution to calculate the CLD from PSD for 2-dimensional ellipsoidal particles is given using the probability apportioning method (Liu and Clark, 1995; Liu et al., 1997; Tadayyon and Rohani, 1998; Li and Wilkinson, 2005). The calculation of CLD from PSD for non-ellipsoidal 2-dimensional has been well developed by (Langston and Jones, 2001) and (Ruf et al., 2000). The CLD is determined by randomly cutting simulation. According to (Li and Wilkinson, 2005), the chord probability distribution for a given PSD of non-spherical particle is determined by randomly cutting simulation, which is not accurate and depends strongly on the assumption made in the calculation.

In the last three years, (Li and Wilkinson, 2005) proposed a general model to translate a PSD into its corresponding CLD given for different shapes including spherical, ellipsoidal and general non-spherical but regular particles.

For a 3-dimensional particle, (Worlitschek, 2003) adopts a 3D representation of the solid particles. The shape of the particle is simply defined in 3D space by an ellipsoid equation. The 
chord probability distribution is developed by its 2-dimensional projections at every orientation.

However, in none of these studies the case of aggregates was studied. Therefore, in this paper, a new algorithm is proposed to build a random aggregate and calculate its CLD.

\section{Experimental devices and procedure}

\section{II.1. Materials}

The organic liquid phase is a $\mathrm{C} 10-\mathrm{C} 13$ cut which is delivered by TOTAL-Solvents under the commercial denomination: Kerdane. As this oil does not present any natural emulsifying property, an anti-agglomerant additive (IPE 202, patented by IFP) is added to the organic phase.

For tests performed on the Archimede loop, the gas phase is pure methane (99.99\%) from AIR LIQUIDE. For tests performed on the Lyre loop, the gas phase is network natural gas. Its average composition is given in Table 1.

Table 1. : Network natural gas composition.

\begin{tabular}{lllllll}
\hline Compound & $\mathrm{CH}_{4}$ & $\mathrm{C}_{2} \mathrm{H}_{6}$ & $\mathrm{C}_{3} \mathrm{H}_{8}$ & $\mathrm{C}_{4+}$ & $\mathrm{N}_{2}$ & $\mathrm{CO}_{2}$ \\
$\%$ mol & 96 & 2 & 0.5 & 0.2 & 1 & 0.3 \\
\hline
\end{tabular}

II.2. Apparatus

Crystallization of water-in-oil emulsions to hydrate slurries under shear was studied with the same model fluids on two flow loops. On both loops, hydrate particle agglomeration is studied through the pressure drop induced by the mixture and the signal provided by the FBRM probe. This paragraph gives descriptions of both loops, of the FBRM probe and the experimental procedures.

Archimede flow loop description:

The Archimede flow loop is located at Saint-Etienne School of Mines. A schema of the apparatus is given in Figure 1.

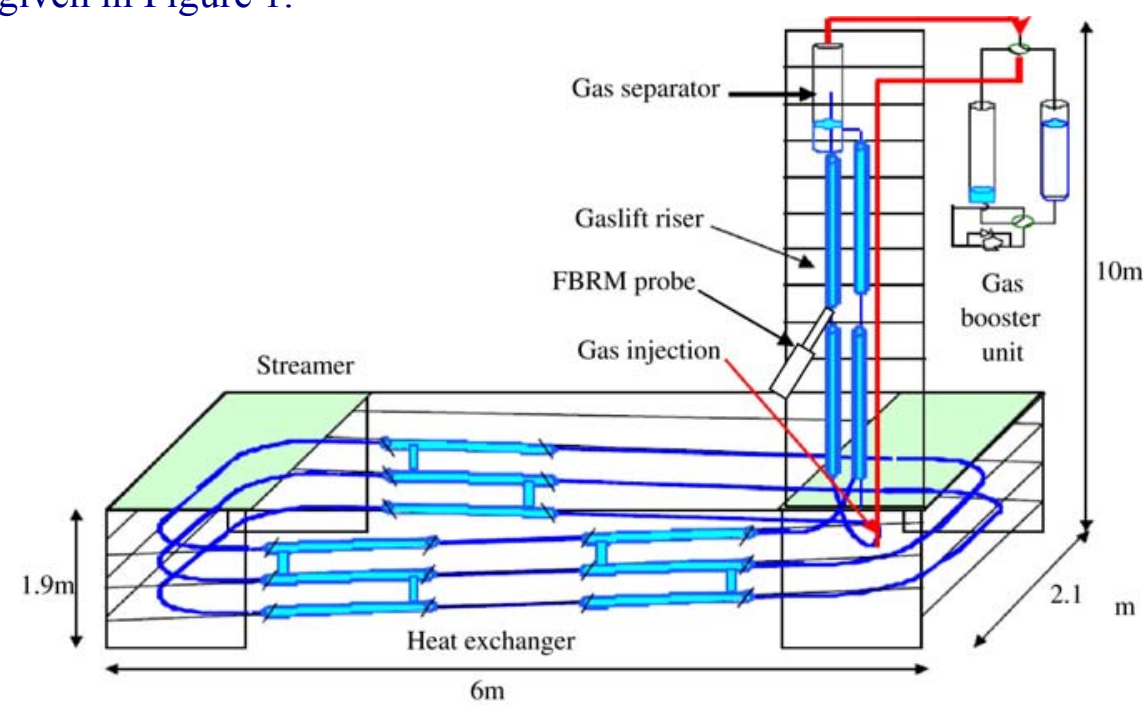

Figure 1: Archimede flow loop.

It was built to reproduce some of the thermodynamic conditions of deep-sea pipelines. Its working pressures are in the range of 1-10 MPa, and temperature can be controlled within the range of $273-283 \mathrm{~K}$. The test section is instrumented with a FBRM probe, several temperature probes, differential pressure probes and a Coriolis flow-meter providing a mass flow rate. The particularity of this loop is that the fluid is motioned throw a gas-lift system. This system can 
only work in laminar flow because his maximum flow rate is $150 \mathrm{~L} \mathrm{~h}^{-1}$. More details on this equipment can be found in (Fidel-Dufour et al., 2006).

Lyre flow loop description:

The Lyre loop is located at IFP-Lyon, it is a multiphase flow loop dedicated to Flow Assurance studies. A simplified schema of the flow loop is given in Figure 2. The test section is entirely temperature-controlled between 273 and $323 \mathrm{~K}$. The test section is instrumented with a FBRM probe, several temperature probes, differential pressure probes and a Coriolis flow-meter providing a mass flow rate and the mixture density. This experimental device allows experiments both in laminar and turbulent flow regimes using a Moineau pump and a flow-rate regulation system. More details on this equipment can be found in (Panchard et al., 2007.

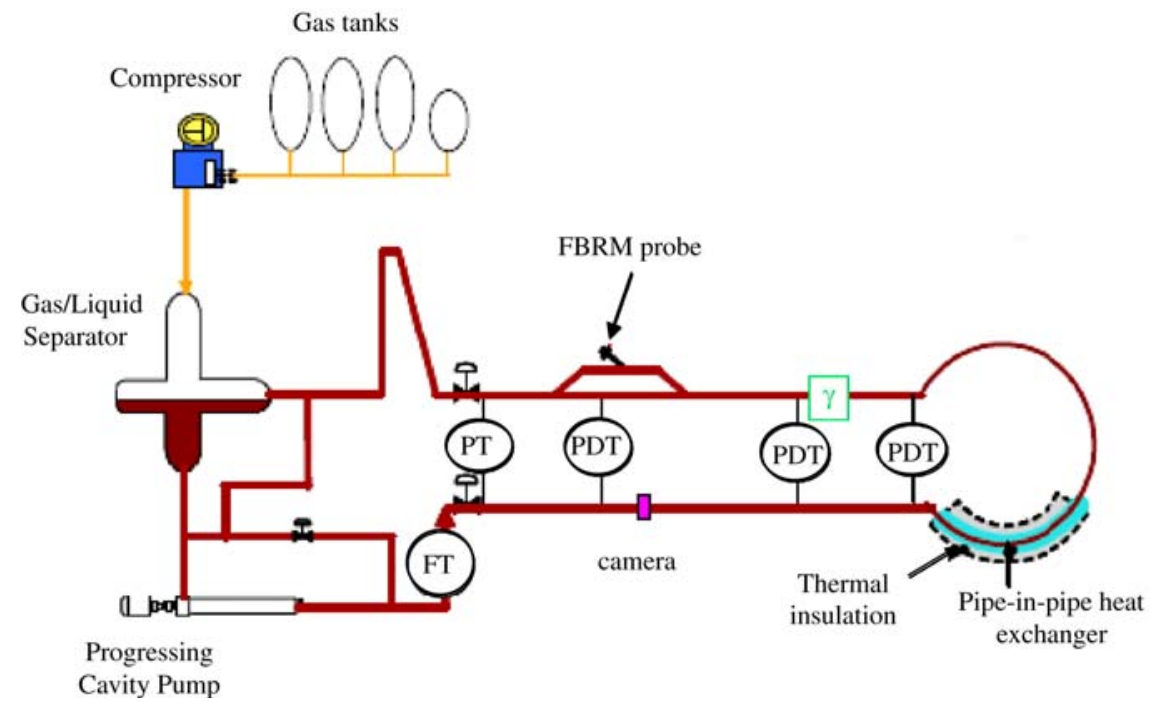

Figure 2: Lyre flow loop.

FBRM probe principle:

The FBRM probe is an in situ particle size analyzer provided by Lasentec. This apparatus consists of an infrared LASER, with a wavelength of $785 \mathrm{~nm}$ and a scan speed from 2 to $8 \mathrm{~m} \mathrm{~s}^{-1}$. When analysing a suspension, the laser emitted from the probe is reflected as it encounters a particle and scans across it, as show Figure 3.

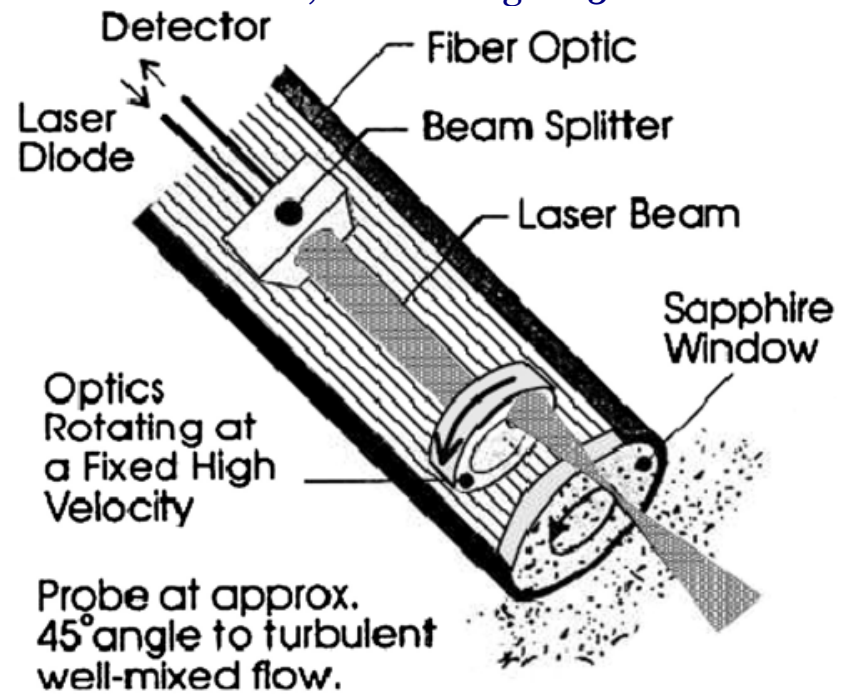

Figure 3: FBRM probe description (from Lasentec ${ }^{\circledR}$ ). 
The chord length is deduced from the reflection time multiplied by the laser scan speed (scan speed in this work is $2 \mathrm{~m} \mathrm{~s}^{-1}$ ). A chord length is a straight line between any two points on the edge of a particle or particle structure (agglomerate). The probe is capable of measuring chord lengths between 0.5 and $1000 \mu \mathrm{m}$. Typically, for concentrated slurries thousands of chords are measured per second. After each measurement duration (set $20 \mathrm{~s}$ in this work), the probe provides an average CLD (chord length distribution), giving the number of chord lengths counted for each size range. For more information on the probe and the technique the reader is referred to the FBRM User's Manual (Mettler-Toledo Lasentec $®$, 2001).
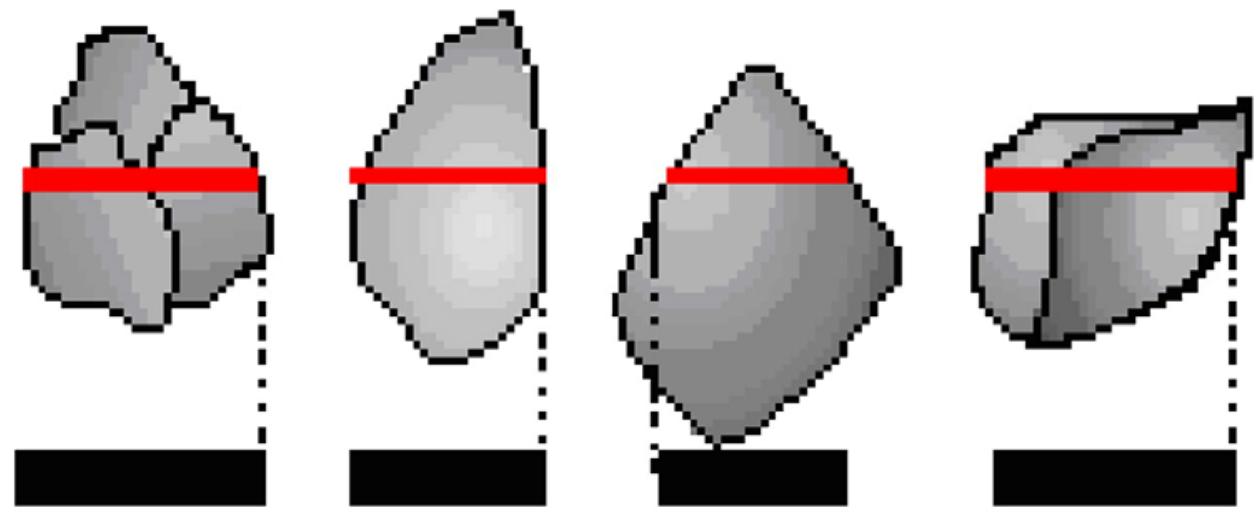

Figure 4: Examples of chord lengths (from Lasentec ${ }^{\circledR}$ ).

Figure 4 provides examples of chord lengths that could be measured on different objects. An important remark is that for a given object, chord lengths can be measured in the range between $\mathrm{o}$ and $D_{\max }$, where $D_{\max }$ is the maximal size of this object. As an illustration, Figure 5 presents the theoretical CLD, calculated for one sphere (Li and Wilkinson, 2005). In the case of a monodispersed population $\left(D_{p}=5 \mu \mathrm{m}\right)$ and in the case of a polydisperse population described with a normal law $\left(D_{p}=5 \mu \mathrm{m}, \sigma=0.3 \mu \mathrm{m}\right)$, FBRM can see $D$ greater than $D_{\max }$ because it cannot distinguish between two particles side-by-side (Greaves et al., 2008). Indeed, in the case of spheres, there is an analytical law giving the probability of measuring a chord length within a given range ( $\mathrm{Li}$ and Wilkinson, 2005). In the case of more complex particle shapes (i.e. agglomerates), the theoretical CLD can be calculated numerically with an algorithm that was developed during this work.

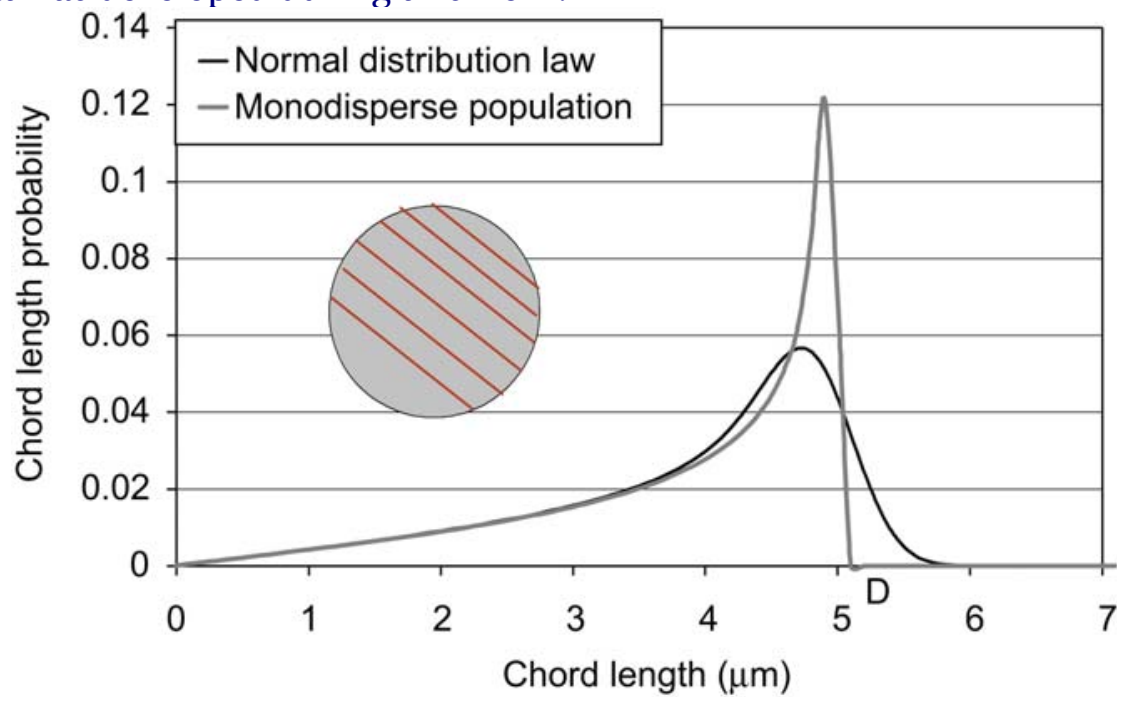

Figure 5: Theoretical CLD for two spheres populations ( $\left.D_{p}=5 \mu \mathrm{m} ; \sigma=0.5 \mu \mathrm{m}\right)$.

The mathematical expressions of the un-weighted and square-weighted mean chord lengths are given below: 


$$
\begin{aligned}
L_{\text {mean }}= & \frac{\sum_{1 \leq i \leq M} f(i) l_{i}}{\sum_{1 \leq i \leq M} f(i)} \\
L_{\text {mean }}^{2}= & \frac{\sum_{1 \leq i \leq M} f(i) l_{i}^{3}}{\sum_{1 \leq i \leq M} f(i) l_{i}^{2}}
\end{aligned}
$$

where $M$ is the number of intervals, $l_{i}$ is the centre of the $i^{\text {th }}$ interval and $f(i)$ the probability of measuring a chord included in the $i^{\text {th }}$ interval.

To have a representative sampling of the population of particles, probes were installed on straight pipes (vertical pipe for the Archimede loop and horizontal pipe for the Lyre loop). The sapphire window of these probes cut the streamlines with an angle of $45^{\circ}$ to the centre of the pipes.

A preliminary work (Le Ba, 2006) was done using FBRM to measure chord length of samples of ceramic particles with a known size. For that a $1 \mathrm{~L}$ batch reactor was used stirred by a fourbladed paddle stirrer at $400 \mathrm{rpm}$. Two sizes of ceramic particles were used: particles with sizes equal to 10 and $100 \mu \mathrm{m}$. The suspensions were prepared with $2 \% \mathrm{wt}$ of particles in $200 \mathrm{ml}$ of water. First a sample of each size was measured by FBRM separately, and after that a mixture of $10 \% \mathrm{wt}$ of $10 \mu \mathrm{m}$ and $90 \% \mathrm{wt}$ of $100 \mu \mathrm{m}$. The measured CLD are in Figure 6.

Some interesting points can be discussed from these curves. Firstly, the FBRM show a bimodal population. Also, for the population with average diameter of about $100 \mu \mathrm{m}$, the apparent PSD was measured using the laser diffraction (Mastersizer 2000S). From this PSD, and assuming it is the true PSD, the true CLD was calculated (using the algorithm which is explained in detail later), and clearly the CLD calculated from the PSD is different from the CLD that is measured experimentally. Two explanations can be given: firstly, the apparent PSD measured from the laser diffraction is different from the true one, and/or, the apparent CLD is different from the true one.

\section{II.3. Emulsion properties}

The emulsions are created adding ultra pure water (Type 1) into the organic phase (Kerdane) which already contains the chemical additive (IPE202). The way emulsions are created is different depending on the experimental flow loop. In the case of tests performed on the Archimede loop, emulsions are created in a reactor with an Ultra-Turrax impeller during $3 \mathrm{~min}$ at $8000 \mathrm{rpm}$. Three measures of the CLD were made: before circulation in the loop, after $5 \mathrm{~h}$ of circulation in the loop and after $24 \mathrm{~h}$ without circulation. The results of the three CLD measurements were the same which evidenced the stability of the emulsion. In the case of tests performed on the Lyre loop, emulsions are created in the flow loop, maintaining the flow at constant high velocity $\left(2 \mathrm{~m} \mathrm{~s}^{-1}, \operatorname{Re} \sim 35000\right)$ during $24 \mathrm{~h}$. As the system is highly sheared, and with the help of a chemical additive, the emulsion obtained was fine and stable. The difference between the procedures to do the emulsion has a consequence in the size of the droplets: for the Lyre loop they are between 4 and $7 \mu \mathrm{m}$ and for the Archimede loop between 7 and $10 \mu \mathrm{m}$. This evidence was confirmed by observing the fresh made emulsion with an optical microscope (see Figure 7). 

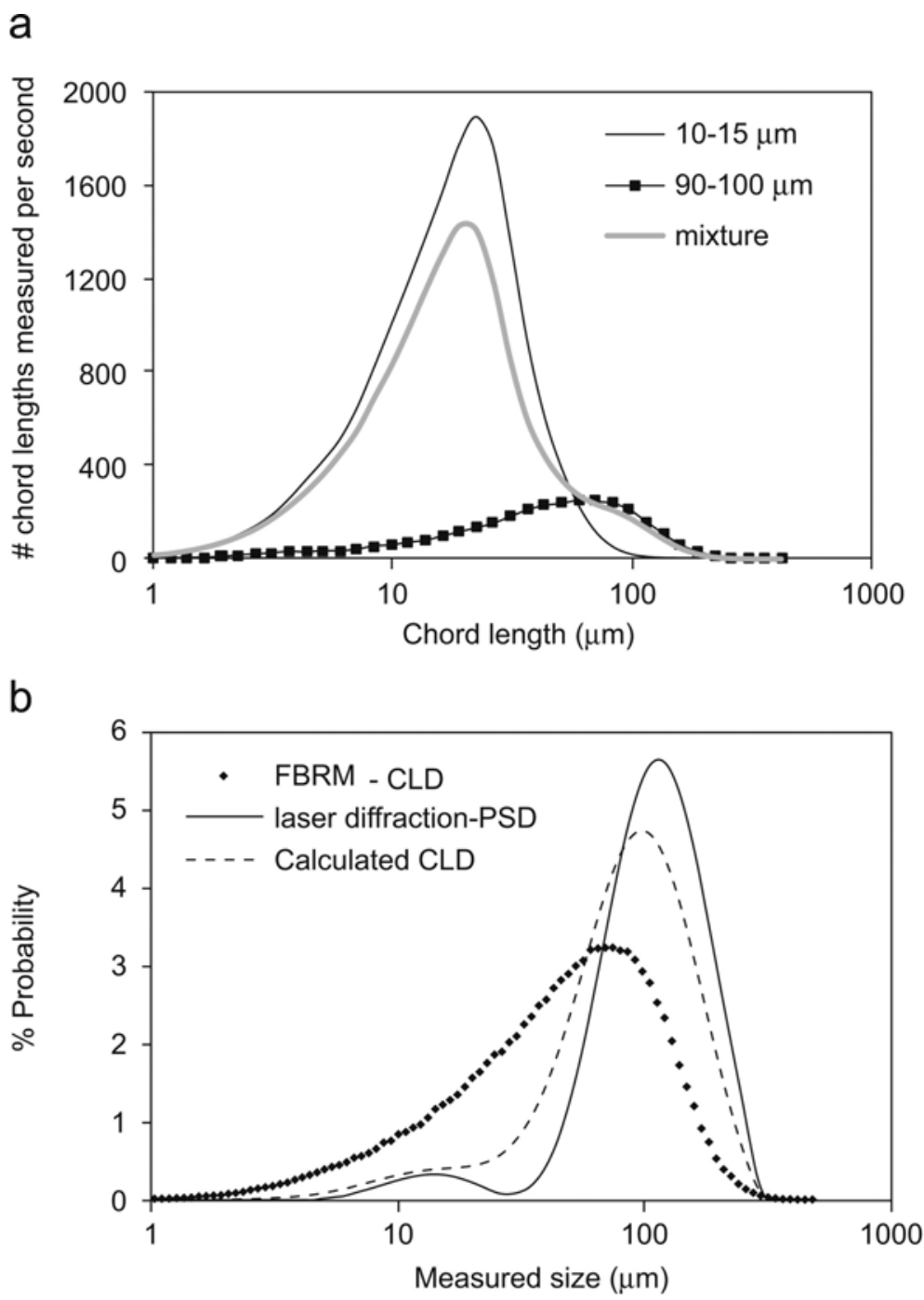

Figure 6: (a) FBRM measurements are carried out at $2 \%$ volumetric ceramic concentration in water and (b) comparison of the particle size distribution from the laser diffraction and the chord length distribution of the FBRM.

\section{II.4. Experimental procedure}

For both experimental flow loops, the first step is the formation of the emulsion and/or loading the loop with it.

After that in the Archimede loop, the emulsion is first cooled down and once the temperature target reached the methane is injected until $8 \mathrm{MPa}$. The gas dissolution in the oil phase induces a pressure loss compensated with a second gas injection until the same pressure. Then the pressure decreases to a constant value and the hydrate crystallization begins.

In the Lyre loop, the natural gas phase is loaded (Figure 2) until the working pressure $7 \mathrm{MPa}$ at $303 \mathrm{~K}$. The pressure decreases when natural gas is dissolved in the oil phase but in this loop a gas injection system maintains the pressure constant. Then the temperature is progressively decreased until $277 \mathrm{~K}$. 


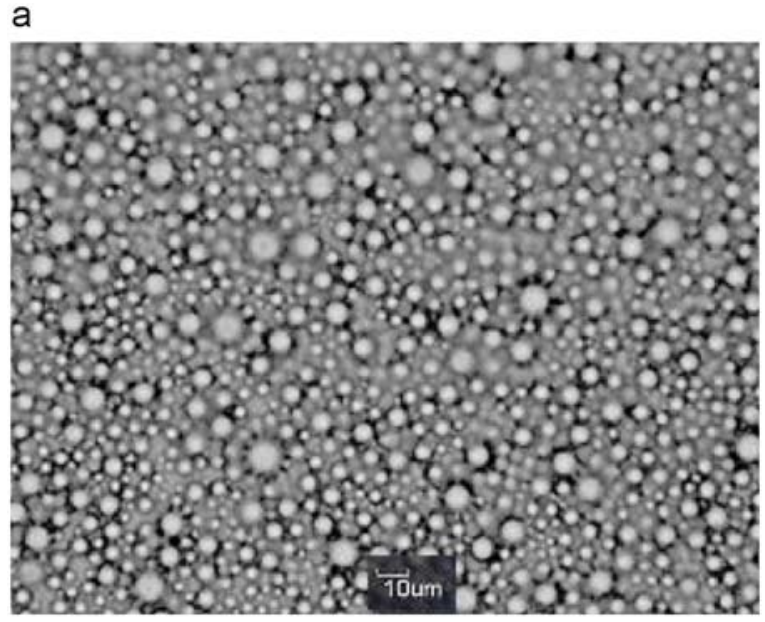

b

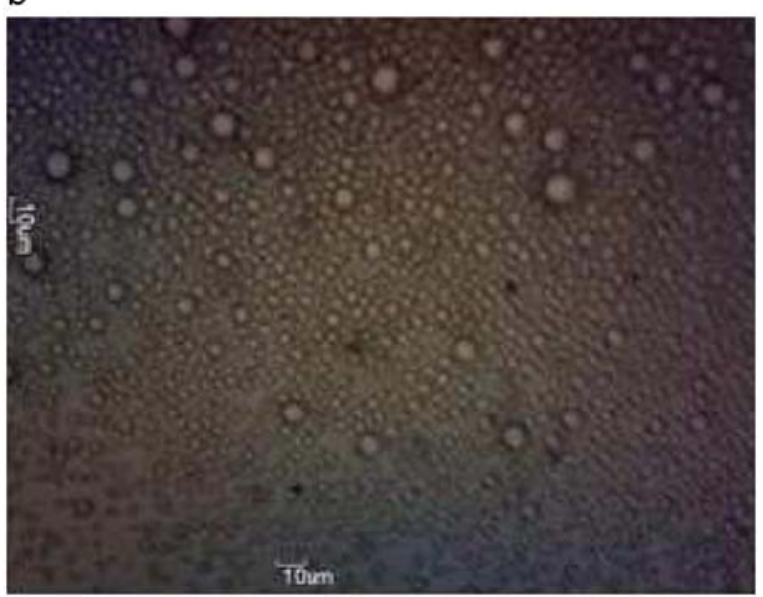

Figure 7: Microscope image of the water-in-oil emulsion (20\% vol. of water): (a) emulsion in Archimede loop and (b) emulsion in Lyre loop.

\section{Modelling}

To interpret the measures made with the FBRM probe a model was developed. This model starts by the construction of an aggregate with three given characteristics, after that the aggregate is scanned as the FBRM probe does and the CLD is calculated.

III.1. 3D Aggregate construction

The first step is to build the 3D aggregate in a way as close as possible to the real hydrate aggregate. The first assumption concerns the primary particles, as they form from water droplets in the emulsion, their shape can be considered as spherical with the same size that water droplets (Camargo and Palermo, 2002; Turner et al., 2005; Fidel-Dufour et al., 2006). This is confirmed by Figures 19 and 23, where in both loops, after the beginning of crystallization the average size remains constant.

The second assumption is to consider that hydrate aggregates are fractal-like objects, like in the previous works (Camargo and Palermo, 2002; Fidel-Dufour et al., 2006). In this case, they can be characterised by a fractal dimension $D_{f}$, a number of droplets $N_{p}$ of individual radius $r$ $\left(r=D_{p} / 2\right)$ and a radius of gyration $R_{g}$. Those characteristics are related through the following statistical scaling relationship (Equation (1)) (Filippov et al., 2000) with a structure factor $k_{f}$ :

$N_{p}=k_{f}\left(\frac{R_{g}}{r}\right)^{D_{f}}$ 
The structure factor was taken equal to 1 . This is the limiting case (Equation (5)) for one sphere, when $R_{g}=r$ at wathever $D_{f}$, then $k_{f}$ must be equal to 1 .

The gyration radius $R_{g}$ is defined as the mean square of the distances between the primary spherical particles and the geometrical mass centre of the aggregate:

$R_{g}{ }^{2}=\frac{1}{N_{p}} \sum_{i=1}^{N_{p}}\left(O_{i}-O_{\mathrm{o}}\right)^{2}$

With $O_{o}=\frac{1}{N_{p}} \sum_{i=1}^{N_{p}} O_{i}$

where $O_{i}$ and $O_{\mathrm{o}}$ are, respectively, the locations of the centres of the $i$ th spherical particle and of the aggregate.

The third and last assumption concerns the structure of these aggregates. Two different mechanisms can be found in the literature: the PCA (particle-cluster aggregation) and the CCA (cluster-cluster aggregation). The first describes the agglomeration between a single particle and an aggregate; whereas the second describes the agglomeration between two aggregates. These two mechanisms were simulated to build numerical aggregates: in the PCA algorithm, a new particle is randomly added to the aggregate until $N_{p}$ primary particles whereas the CCA algorithm corresponds to the random aggregation of several smaller aggregates. In reality agglomeration is the result of the collision between aggregates and the agglomeration between primary particles mainly in the very early times of the agglomeration. The PCA mechanism is described in details by (Mackowski, 1995 Filippov et al., 2000) and a generalization of the tunable cluster-cluster aggregation (CCA) method of (Thouy and Jullien, 1994; Filippov et al., 2000) is also given. In this paper, a new algorithm is proposed to build a random aggregate following PCA and CCA mechanisms. The main difference of this new algorithm for PCA and CCA is the way the new sphere is added randomly to the aggregate. The position of the new sphere is determined by the "Cartesian coordinates" (Equation (8)) (see below).

The PCA and CCA algorithms used in this study are detailed step by step below. For each algorithm the inlet parameters are the primary particles diameter, the structure factor, the fractal dimension of the aggregate and the total number of particles in the aggregate.

\section{III.1.1 PCA algorithm of aggregate construction}

The inputs of the algorithm are the number of spheres $N_{p}$ with a radius $r\left(r=D_{p} / 2\right)$ from which the aggregates will be constructed a set of $N_{p}$ spheres and a common value of the radius $r$ for all the spheres.

* Fix randomly a position of the space $\left(x_{0}, y_{0}, z_{0}\right)$ which will be the centre of the first sphere.

* Make a random pull of two angles $\theta$ and $\varphi(0 \leq \theta \leq 2 \pi, 0 \leq \varphi \leq \pi)$. These two angles will fix the direction of a new sphere, stucked on the previous one. The coordinates of this new sphere will be:

$$
\begin{aligned}
& x_{i}=x_{0}+2 r \cos \theta \sin \phi \\
& y_{i}=y_{0}+2 r \sin \theta \sin \phi \\
& z_{i}=z_{0}+2 r \cos \phi
\end{aligned}
$$

* Check that the new sphere does not occupy a space already occupied by a sphere generated previously: verifying that $\forall i j,\left\|\overrightarrow{O_{i} O_{j}}\right\| \geq 2 r$. Also verify that $D_{f}$ obeys the scaling relationship (Equation (5)) with $k_{f}$ equal to 1. 
* Choose randomly a sphere of the aggregate which will become the new centre of the aggregate with coordinates $\left(x_{0}, y_{0}, z_{0}\right)$ and continue from step 2.

Figure 8 shows an example of an aggregate constructed with 100 primary particles or spheres using PCA algorithm as described above. The fractal dimension value was set equal to 2.2.

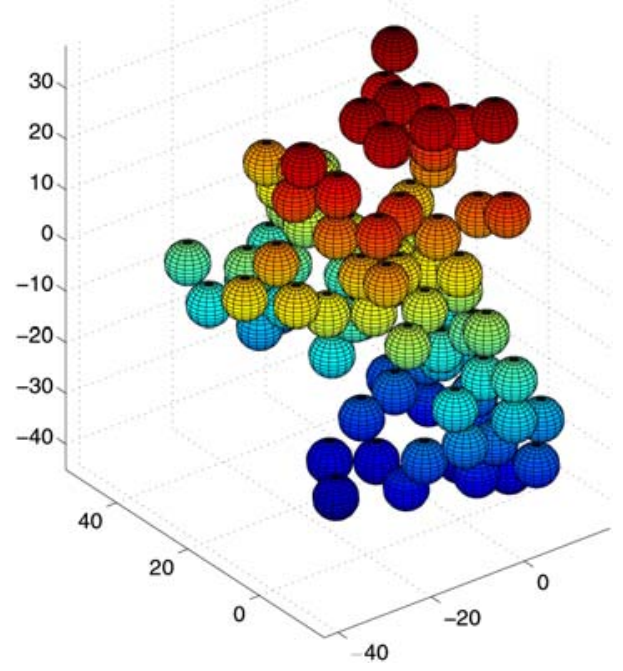

Figure 8: Example of an aggregate of 100 spheres with $D_{f}$ equal to 2.2 generated by PCA algorithm $\left(N_{p}=100, D_{f}=2.2, k_{f}=1.0, D_{p}=5 \mu \mathrm{m}\right)$.

III.1.2 CCA algorithm of aggregate construction

As for the PCA algorithm, the number $N_{p}$ of spheres with radius $r$ from which the aggregate will be constructed are fixed and followed by:

* Build an aggregate (called initial aggregate) by the PCA algorithm for which the number of particles $N_{p_{1}}$ is randomly chosen $\left(N_{p_{1}} \leq N_{p}\right)$ with prescribed values of $D_{f}$ and $k_{f}=1$ (Lee et al., 2000).

* Choose randomly a particle of the initial aggregate in which some space is sufficient for sticking a new particle. This new particle will become $\left(x_{0}, y_{0}, z_{0}\right)$ to pursue the construction of a new containing aggregate $N_{p 2}$ particle $\left(N_{p_{2}} \leq N_{p}-N_{p 1}\right)$.

* Check that all spheres of the new aggregate are not intersected by the spheres of the initial aggregate. That consists in verifying that $\forall i j,\left\|\overrightarrow{O_{i} O_{j}}\right\| \geq 2 r$ and that $D_{f}$ obeys to the scaling relationship (Equation (5)).

Figure 9 illustrates the principle of CCA algorithm.

Figure 10 shows an aggregate of 100 particles generated with CCA algorithm. The fractal dimension and structure factor values were set to $D_{f}=2.2$ and $k_{f}=1.0$.

In the further modelling only CCA mechanism was used because in real systems from experiments the agglomeration mechanism observed is mostly by CCA.

III.2. CLD calculation from the constructed aggregate

In order to calculate the CLD of the aggregates constructed before an algorithm was constructed. The aggregate constructed is projected in a plan and scanned as the FBRM does. The chord lengths measured by this way are then organised in a chord length distribution. The same aggregate is then rotated and projected again in the same plan and the CLD calculated. 


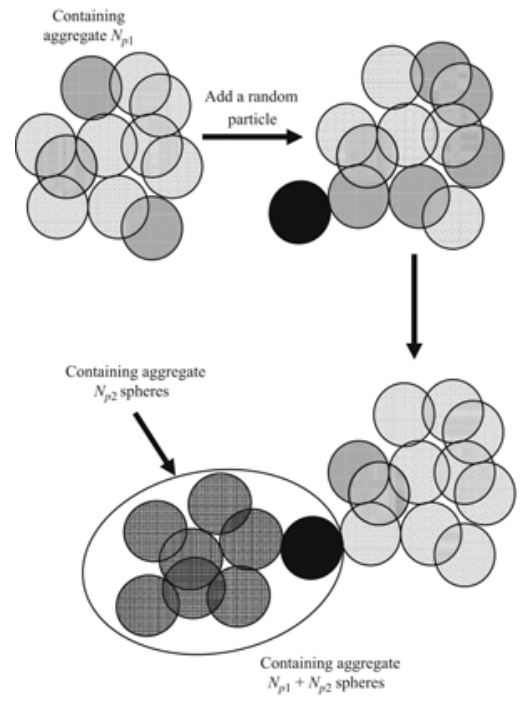

Figure 9: CCA algorithm.

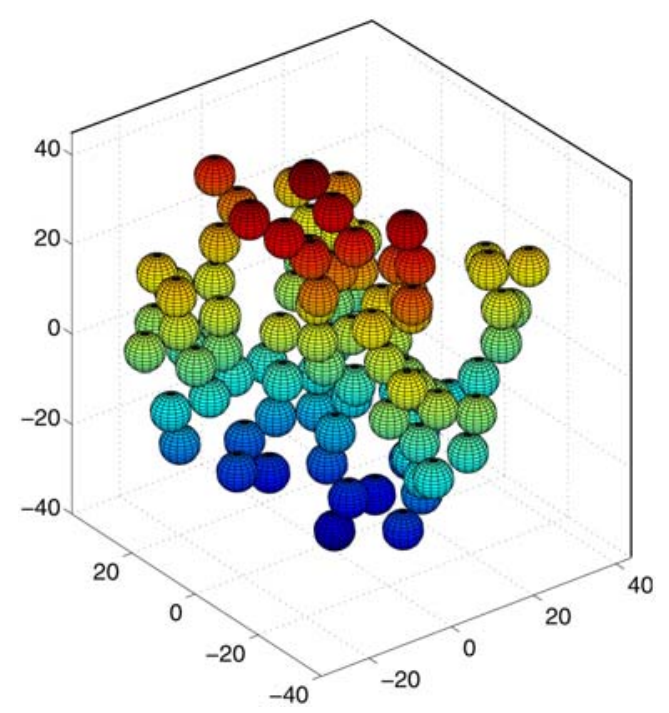

Figure 10: Example of an aggregate of 100 spheres with $D_{f}=2.2$ generated by $C C A$ algorithm $\left(N_{p}=100, D_{f}=2.2, k_{f}=1.0, D_{p}=5 \mu \mathrm{m}\right)$.

This procedure is repeated and an average CLD is calculated. The input parameters are the number of rotations of the aggregate and the number of scans $N$ (see Figure 11). The algorithm steps are detailed below:

1. Random rotation of the aggregate and a projection on the plan $(x \circ y), P_{1}=1$.

- Select three random rotation angles and compute the new coordinates of the $N_{p}$ particle centres after rotation by the Euler theorem.

- Project the aggregate on the plan (xoy) (as illustrated in Figure 11).

2. Calculation of the CLD.

- Determine $x_{\min }$ and $x_{\max }$ (see Figure 10).

- For $\left.x_{i}=x_{\min }+i\left(x_{\max }-x_{\min }\right) / N\right)$ where $N=\left(x_{\max }-x_{\min }\right) / \Delta x, I \in[0, N]$, compute $y^{+}$and $y^{-}$ (intersection of each projected circle with $x=x_{i}$ ).

- Account for possible overlapping of the projected particles in order to obtain the largest couple $\left(y^{+}, y^{-}\right)$such that a continuous chord symbolizes a chord length $l_{i}$ (see Figure 11). 
3. $\underline{P}_{n}=\underline{P}_{n-1} \underline{1}$; while $\underline{P}<\underline{P}_{\max }$ return to (1).

The distributed chord lengths generated through the previous algorithm were stored into 38 or 90 logarithmically spaced channels, which correspond to the output of the Lasentec/Mettler Toledo FBRM probe (Model 6ooDL).

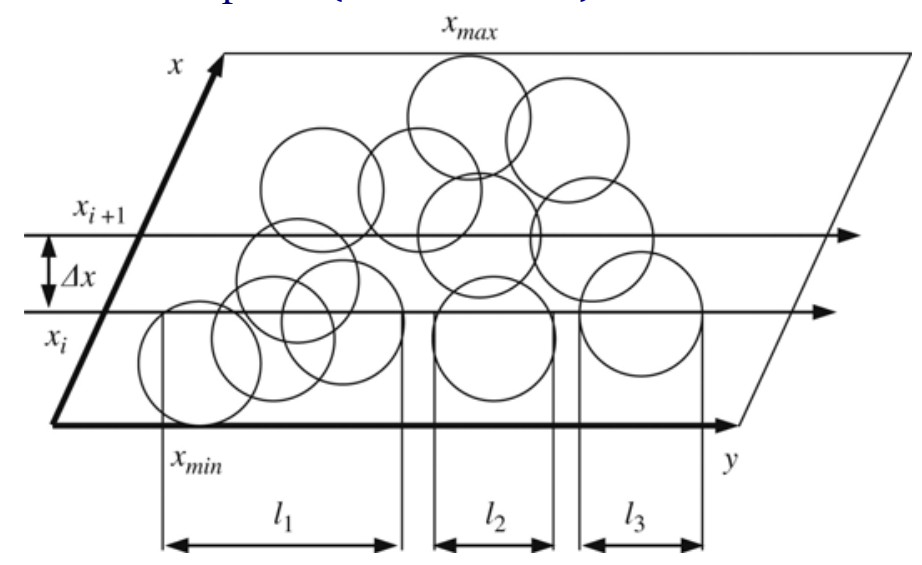

Figure 11: Principle of the computation of the chord lengths $l_{1}, l_{2}$ and $l_{3}$ on a random $2 D$-projection of a simulated aggregate.

Figure 12 shows an algorithm for calculating the number of primary particles and the fractal dimension of an aggregate.

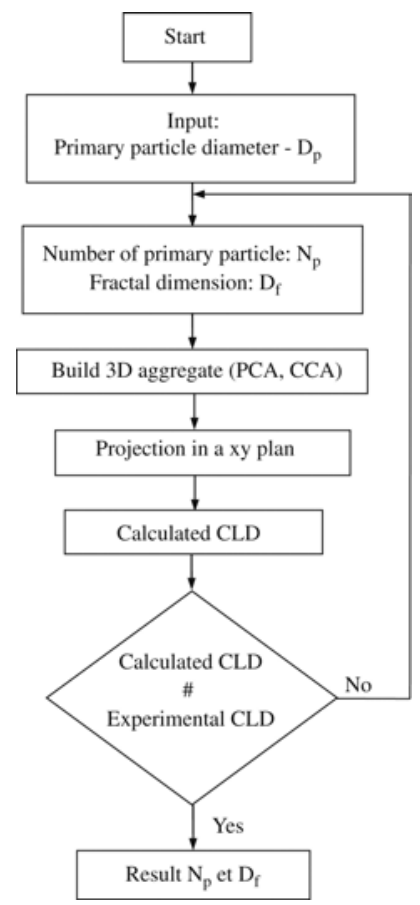

Figure 12: Algorithm for calculating the number of primary particles and the fractal dimension of an aggregate.

A study was made on the influence of the number of projections on the CLD. Figure 13 displays the CLD of the same aggregate $\left(N_{p}=30, D_{f}=2.5\right)$ but with varying numbers of projections $P$.

It should be noted that the simulated CLD profile becomes stabilized after 50-200 random rotations and projections (Figure 13). The number of projections is therefore set to 200 .

To test the construction of random aggregates and his influence on the CLD two aggregates with the same parameters $\left(N_{p}, D_{f}, k_{f}, D_{p}\right.$, ) were constructed and then the CLDs calculated. 


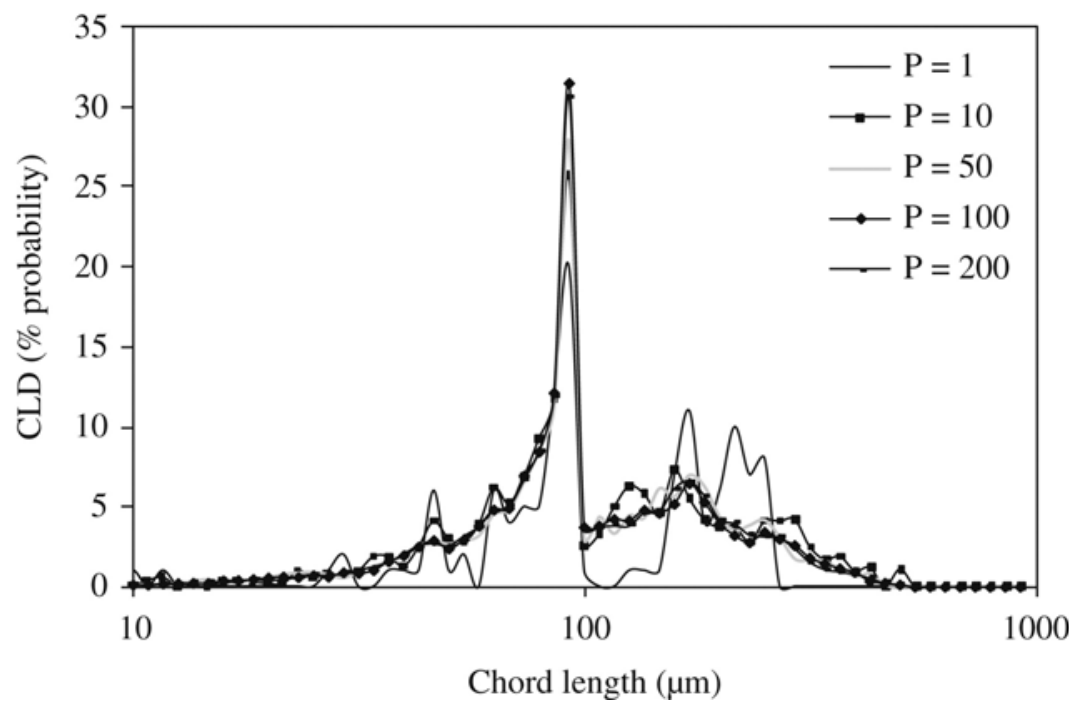

Figure 13: Simulated CLD with different number of projections $\left(N_{p}=100, D_{f}=2.2, k_{f}=1.0, D_{p}=100 \mu \mathrm{m}\right)$.

Figures 14, 15 and 16 display the comparison between CLDs of two different CCA aggregates characterized by the same $N_{p}, D_{f}, k_{f}$ and $D_{p}$. From Figures 14, 15 and 16, is presented the effect of $D_{f}$ on the aggregate compactness and on the CLD shape.

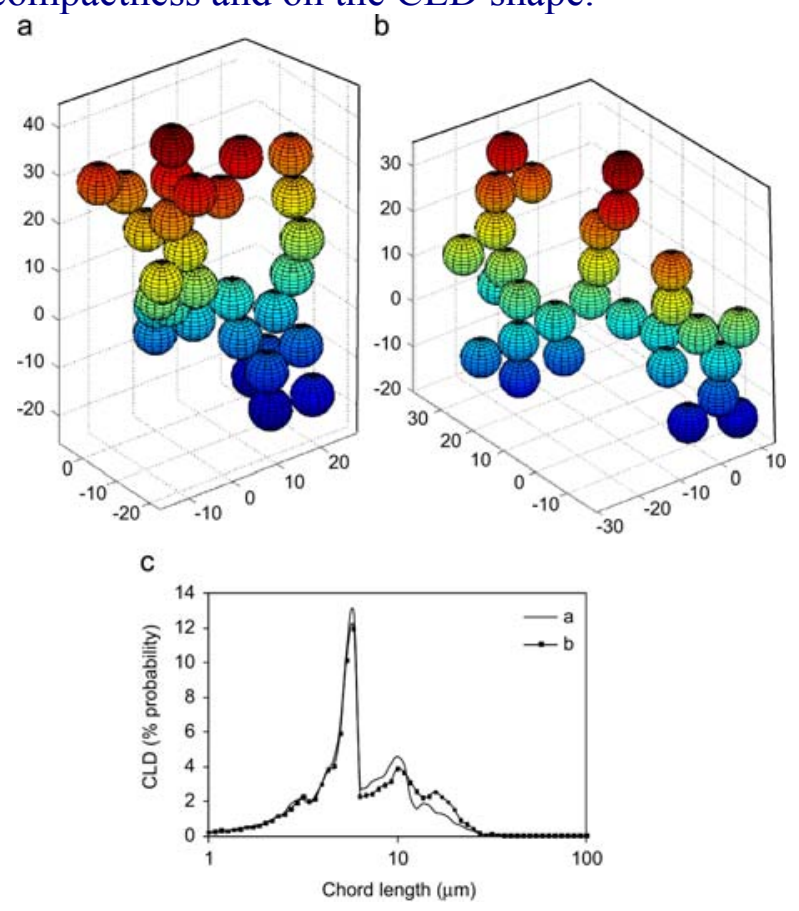

Figure 14: CLD of two random aggregates made of 30 spherical primary particles with $D_{f}$ equal to $1.8\left(N_{p}=30, D_{f}=1.8, k_{f}=1.0, D_{p}=8 \mu \mathrm{m}\right)$.

For Figures 14, 15 and 16, even if they look rather different, the aggregates with the same fractal dimension have a similar CLD.

Consequently, the fractal dimension $D_{f}$ of aggregates which is a measure of the compactness of the aggregate is a relevant parameter for the CLD shape.

First simulations turn out that, in general, a well defined and rather sharp peak is obtained on each CLD which is clearly associated to the size of the primary particles. 
a

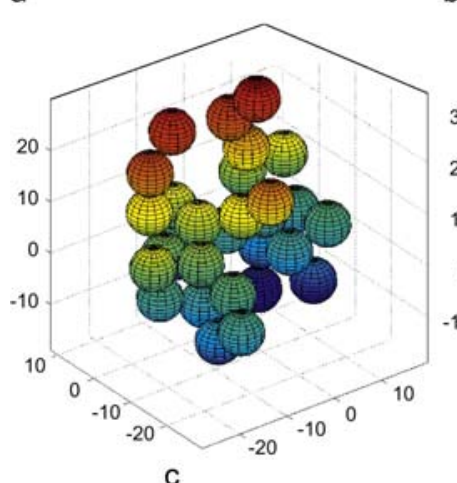

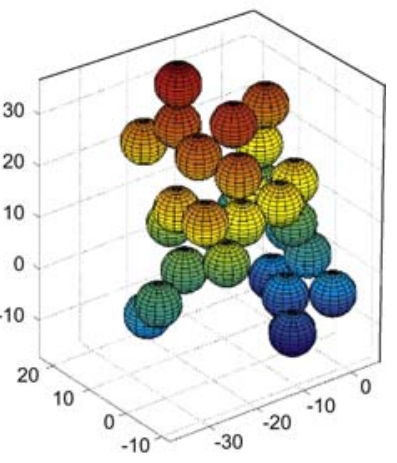

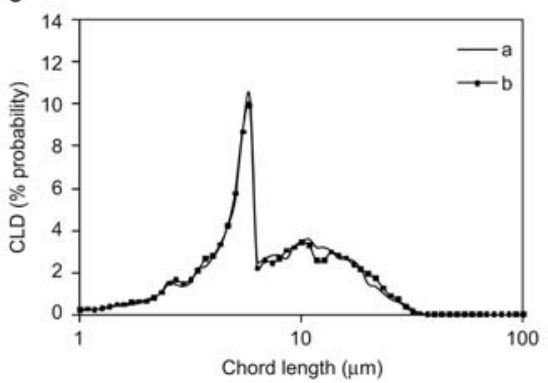

Figure 15: CLD of two random aggregates made of 30 spherical primary particles with $D_{f}$ equal to $2.2\left(N_{p}=30, D_{f}=2.2, k_{f}=1.0, D_{p}=8 \mu \mathrm{m}\right)$.

a

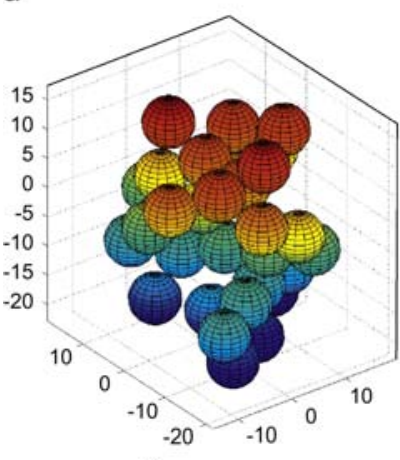

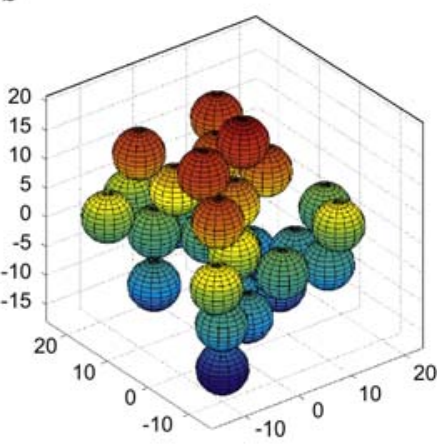

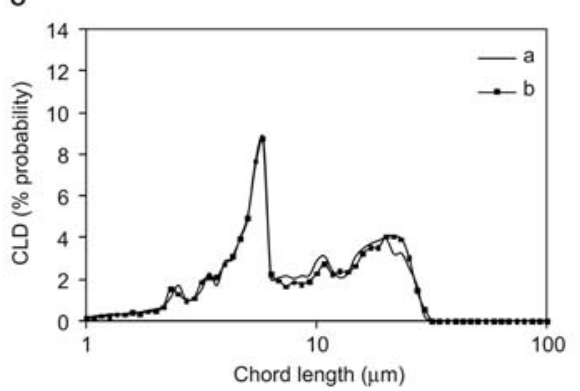

Figure 16: CLD of two random aggregates made of 30 spherical primary particles with $D_{f}$ equal to $2.6\left(N_{p}=30, D_{f}=2.6, k_{f}=1.0, D_{p}=8 \mu \mathrm{m}\right)$.

Furthermore, a second rather wide and irregular distribution of counts is found to be associated to aggregates of several particles. As $D_{f}$ increases, the peaks at higher chords lengths increase. The compactness of the aggregates has an influence on the probability of measuring chord lengths cutting more than two primary particles as illustrated on Figure 17, more compact aggregates (i.e. characterized by larger values of $D_{f}$ ) can be characterized through the displacement of the larger modes towards increasing chords lengths and by an increasing of the height of peaks at this lengths. 


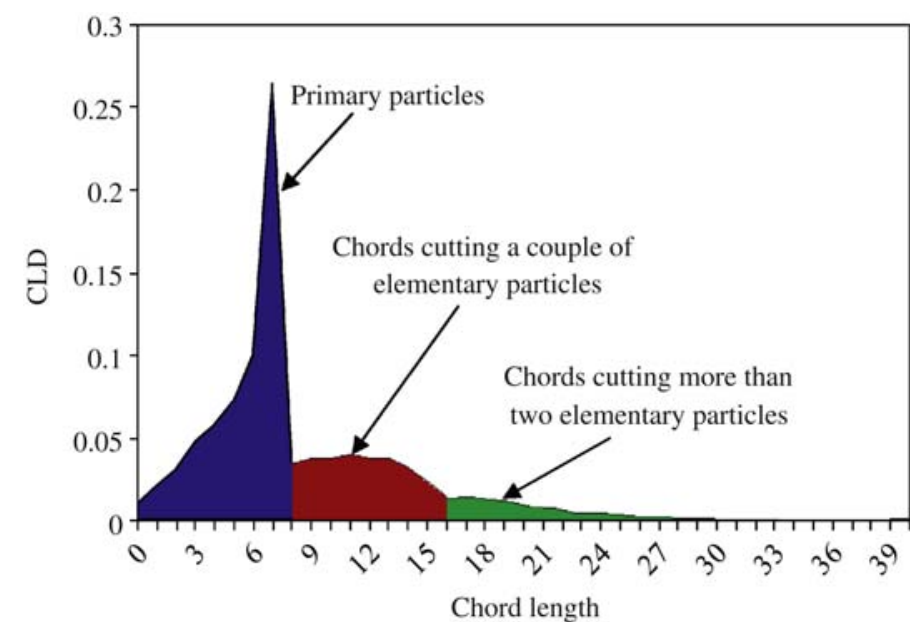

Figure 17: Schematic decomposition of the CLD.

\section{Experimental results and discussion}

\section{IV.1. Hydrate crystallization in the Archimede flow loop}

In the Archimede flow loop a test was performed with an emulsion of $30 \%$ volume of water in the liquid phase, and $0.5 \%$ (wt/wt water) of additive of methane hydrates crystallization at $277 \mathrm{~K}$ and $7 \mathrm{MPa}$ pressure.

Figure 18 presents the evolution of temperature and pressure during the test performed on the Archimede loop, under a laminar flow ( $\operatorname{Re} \sim 210$ at the beginning of the test).

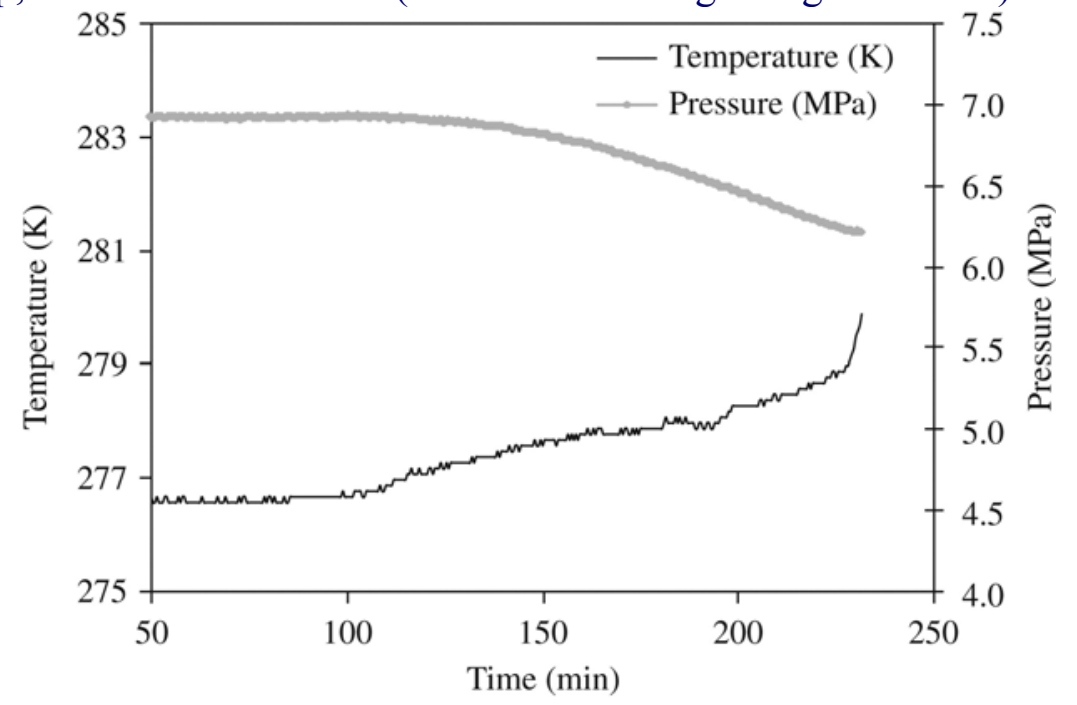

Figure 18: Pressure and temperature evolution during a test on the Archimede loop (Archimede, $T=277 \mathrm{~K}, P=7 \mathrm{MPa}$, 30\% water (Vwater $/ V$ ), $0.5 \%$ add (wt/wt water)).

As the emulsion is placed under subcooling conditions, the exothermic crystallization of hydrate is evidenced by a temperature increase. This temperature increase is associated to a pressure decrease because of gas transfer from the emulsion into the hydrate phase. On this figure the beginning of hydrate crystallization is detected at $t \sim 100 \mathrm{~min}$.

The evolution of the friction coefficient is compared to the mean chord length given by the FBRM probe in Figure 19. The friction coefficient is related to the linear pressure drop $(\Delta P / L)$ and to the fluid velocity $(u)$ through the following equation (Bird et al., 1960):

$\left|\frac{\Delta P}{L}\right|=f \frac{2 \rho u^{2}}{D}$ 
where $\Delta P$ is the measured pressure drop across a length $L, u$ is the measured velocity, $D$ is the internal diameter of the flow loop, and $\rho$ is the density of the fluid.

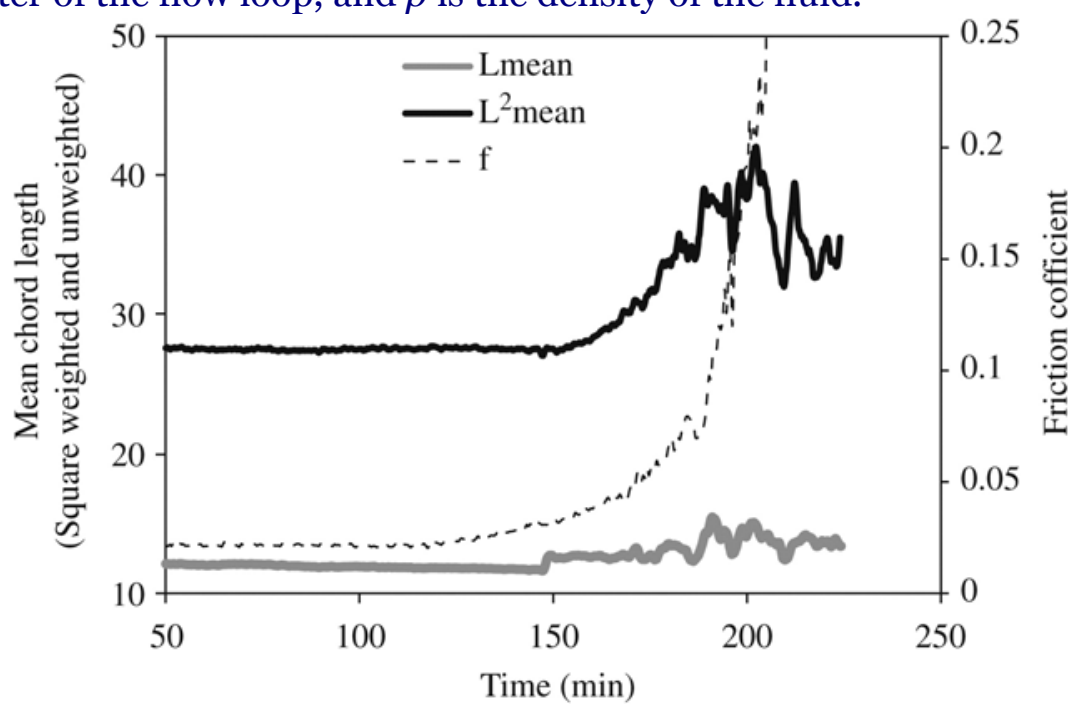

Figure 19: Mean chord length measured during the Archimede loop test ( $L_{\text {mean }}^{2}$ is square weighted, $L_{\text {mean }}$ is unweighted) (Archimede, $T=277 \mathrm{~K}, \mathrm{P}=7 \mathrm{MPa}$, 30\% vol. water, $0.5 \%$ add. (wt/wt water)).

Two different mean chord lengths (Equations (3) and (4)), calculated at each step of time are proposed. $\underline{L}_{\text {mean }}$ stands for the number average value of the CLD, $L_{\text {mean }}^{2}$ is a surface average value, i.e., weighted by the square value of the chord length.

The interest of using such weighted average value is to emphasize changes among the largest chord length (Heath et al., 2002), which have lower probability of being measured.

Figure 19 shows that before hydrate crystallization, the mean chord length measured on the emulsion is constant. Because of the polydispersity of the emulsion the un-weighted and square weighted mean chord lengths are different $\left(L_{\text {mean }} \approx 12 \mu \mathrm{m}, L_{\text {mean }}^{2} \approx 28 \mu \mathrm{m}\right.$ ).

About $50 \mathrm{~min}$ after the beginning (at $t=150 \mathrm{~min}$ ) of the conversion of water into hydrate, the FBRM probe detects a change of the mean size of objects carried in the loop. The squareweighted mean chord length increases in a way comparable to the increase of the friction coefficient. This observation confirms the assumption of hydrate particle agglomeration and its effect on pressure drop.

It is interesting to notice that the viscosity of the mixture increases without any change on the size of the particles detected by the FBRM probe. This observation is discussed hereafter.

Figure 20 gives examples of three instantaneous CLD, respectively, obtained for the emulsion, and for the suspension of hydrate particles.

On the emulsion CLD ( $t=80 \mathrm{~min})$ one can see that the mode corresponds to the mean chord length $\left(L_{\text {mean }}\right)$ and it can be associated to the average diameter of water droplets in the initial emulsion. 


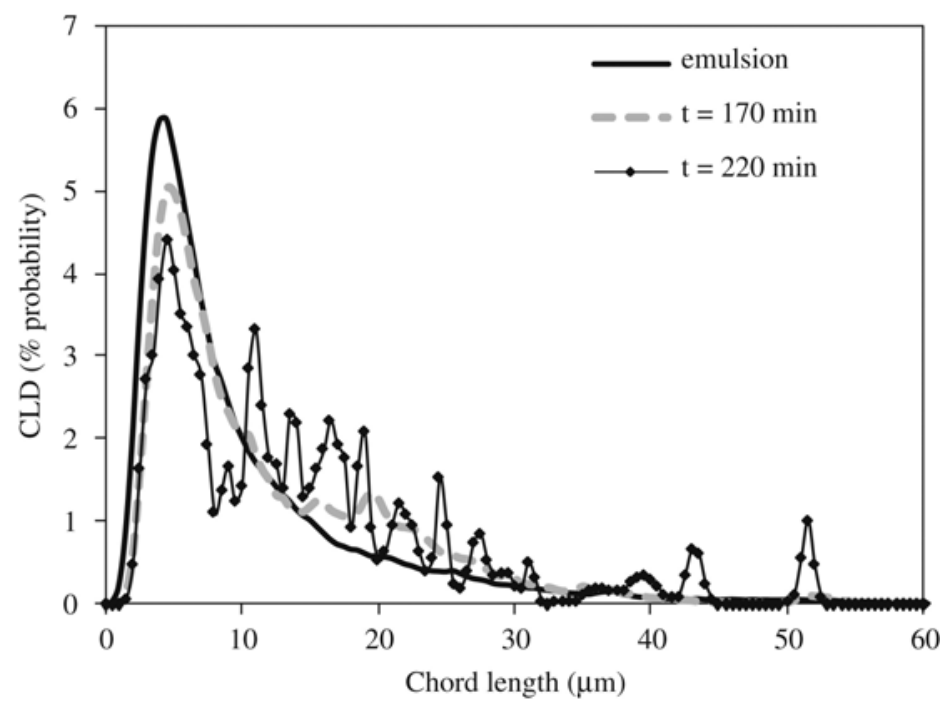

Figure 20: Examples of unweighted CLDs measured during the Archimede loop test (Archimede, $T=277 \mathrm{~K}, \mathrm{P}=7 \mathrm{MPa}$, 30\% vol. water, $0.5 \%$ add (wt/wt water)).

At $t=170$ and $220 \mathrm{~min}$, one can see the influence of agglomeration on the CLD measurement: The intensity of the initial mode tends to decrease while peaks in larger chords lengths are detected and increase. The unevenness of the CLDs obtained for the hydrate slurry are probably linked to the low velocity of the flow on the Archimede loop $\left(<0.2 \mathrm{~m} \mathrm{~s}^{-1}\right)$, and a number of aggregates scanned per second not high enough to obtain a smooth statistical distribution.

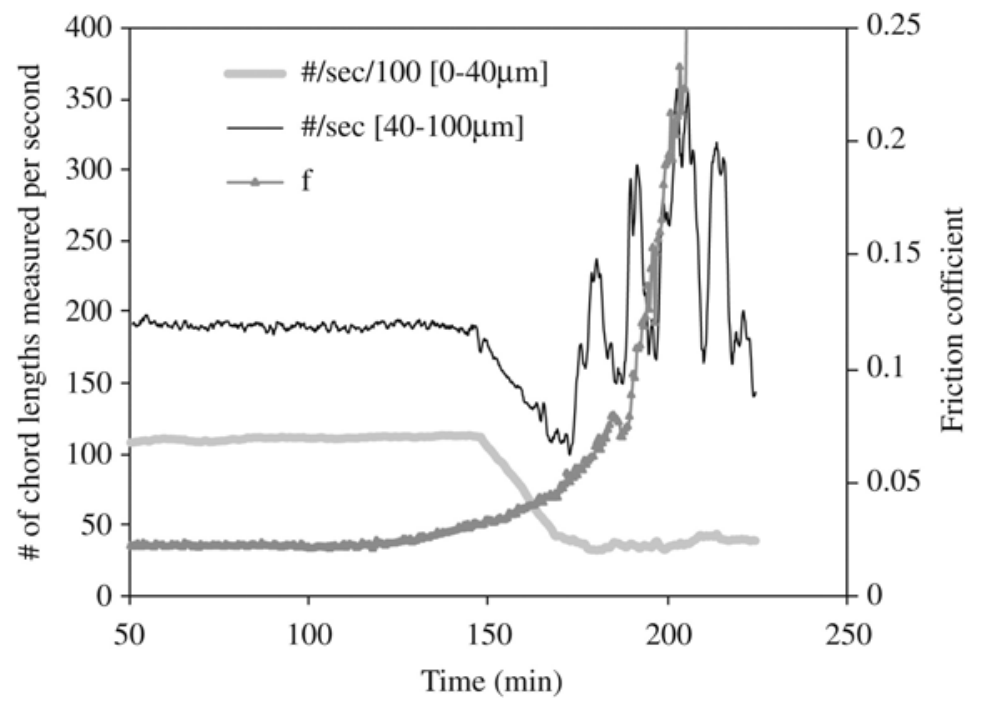

Figure 21: Evolution with time of the number of chords shorter and larger than $40 \mu \mathrm{m}$ measured per second, and of the friction coefficient during the Archimede test (Archimede, T=277 K, $P=7 M P a, 30 \%$ vol. water, $0.5 \%$ add. (wt/wt water)).

Figure 21 presents a comparison between the evolution with time of the friction coefficient and the evolution with time of the number of chords measured per second within two ranges gathering all the chords detected during this test: number of chords $\times 10^{-2} \mathrm{~s}^{-1}(0-40 \mu \mathrm{m})$ and number of chords $\mathrm{s}^{-1}(40-100 \mu \mathrm{m})$. As it can be seen in Figure 21 , the range $(0-40 \mu \mathrm{m})$ contains almost all the chords measured in the initial emulsion. Larger chords $(40-100 \mu \mathrm{m})$ are detected after the beginning of hydrate particles agglomeration. At $t=120 \mathrm{~min}$, the number of chords measured within both ranges decreases. As discussed above, this can be attributed to the mean velocity decrease (through a decrease of the volume of fluid scanned per second). 
After $t=160 \mathrm{~min}$, the number of chords larger than $40 \mu \mathrm{m}$ measured per second steeply increases whereas the number of small chords remains at a low value. This observation confirms agglomeration and justifies the steep increase of the viscosity followed by plug of the pipe.

IV.2. Hydrate crystallization in the Lyre loop

In the Lyre flow loop a test was performed with an emulsion of $30 \%$ volume of water in liquid phase and $0.5 \% \mathrm{wt}$ of additive (in water) of methane hydrates crystallization at $277 \mathrm{~K}$ and $7 \mathrm{MPa}$.

Figure 22 presents the temperature and the calculated friction coefficient from the measured pressure drop (Equation (7)) evolution during a test in the Lyre loop under turbulent flow regime ( $\operatorname{Re} \sim 8500$ at the beginning of the test) at constant pressure equal to $7 \mathrm{MPa}$.

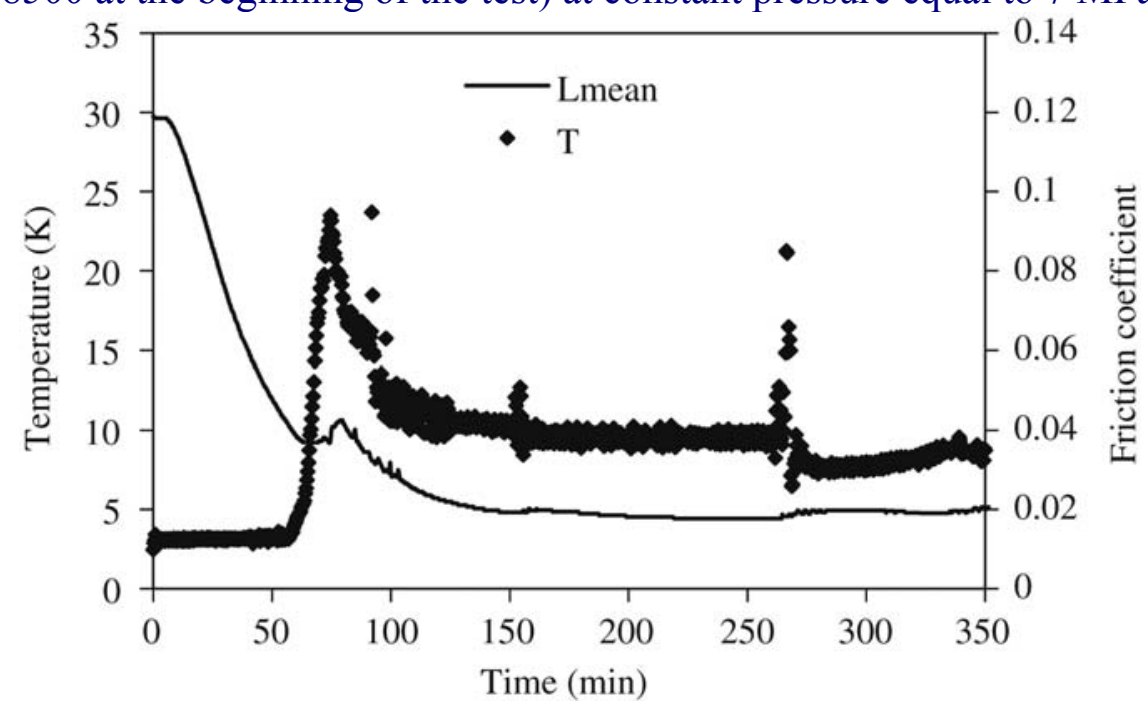

Figure 22: Temperature and friction coefficient evolution during the test on the Lyre loop (Lyre, $T=277 \mathrm{~K}, \mathrm{P}=7 \mathrm{MPa}$, 30\% vol. water, $0.5 \%$ add. (wt/wt water))

Once again, hydrate formation is evidenced with a temporarily temperature increase (at $t=70 \mathrm{~min})$. This is associated to a steep increase of the friction coefficient that reaches a maximum value before coming down to a lower constant value.

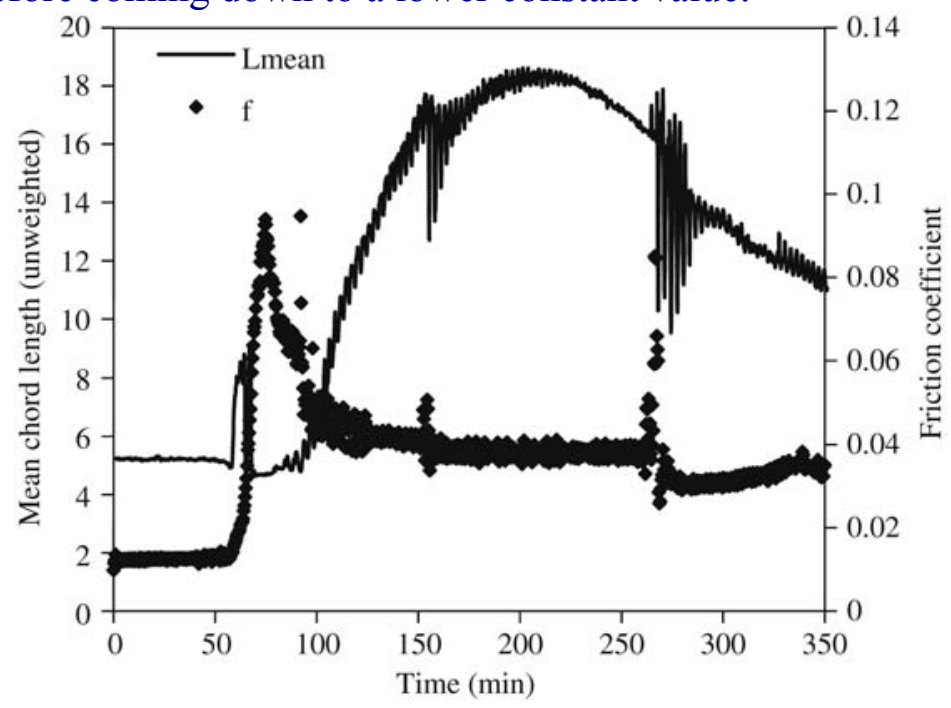

Figure 23: Mean velocity $(u)$, friction coefficient $(f)$ and mean chord length evolution during the test on the Lyre loop (Lyre, $T=277 \mathrm{~K}, \mathrm{P}=7 \mathrm{MPa}, 30 \% \mathrm{vol}$. water, $0.5 \%$ add. (wt/wt water)). 
The conversion of the water-in-oil emulsion into a hydrate suspension increases twice the friction coefficient at the end of the experiment. This steep increase of the friction coefficient is characteristic of turbulent/laminar transition due to the viscosity increase of the slurry.

Figure 23 provides a comparison of the friction coefficient to the mean chord length measured by the FBRM probe along this experiment.

One can see that the initial mean chord length of the emulsion is $5 \mu \mathrm{m}$ (Figures 23 and 24). At $t \sim 50 \mathrm{~min}$, the mean chord length momentarily increases and then decreases and tends to a constant value. On Figure 23, the first peak on $L_{\text {mean }}$ is not due to agglomeration, but to bubbles that are sucked in the gas separator in reason of a transient behaviour as the hydrates form.

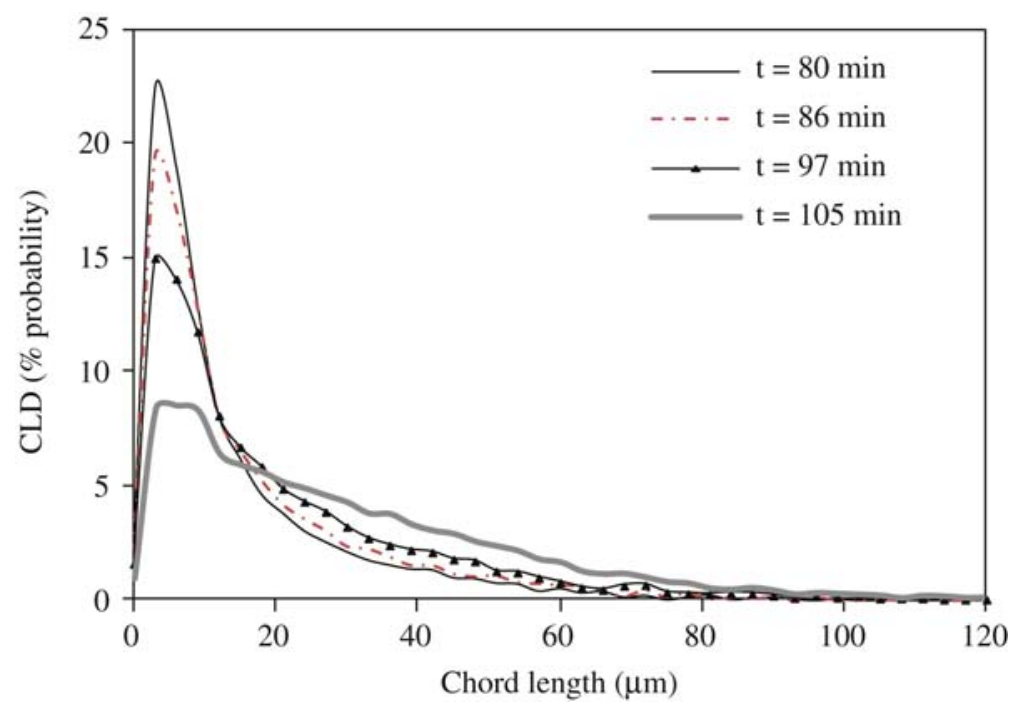

Figure 24: Mean velocity (u), friction coefficient $(f)$ and mean chord length evolution during the test on the Lyre loop (Lyre, $T=277 \mathrm{~K}, P=7 \mathrm{MPa}, 30 \% \mathrm{vol}$. water, $0.5 \%$ add. (wt/wt water)).

So both the experiments from Lyre Loop and Archimede loop present the same behaviour: crystallization occurs without effect on the mean chord length, that means that particles do not agglomerate, but with an influence on the pressure drop. In Figure 23, the pressure drop is modified because of the important methane consumption in the oil phase, and as a result, the viscosity of the oil phase increases. As the oil is re-saturated, the pressure drop (proportional to the friction coefficient $f$ ) returns to a constant value, higher than the initial one in reason of the agglomerates. The appearance of such a peak on the friction coefficient is dependent on the intensity of the crystallization. It can be observed, or not, on the Archimede flow loop and Lyre flow loop. Figure 19 presents an experiment on the Archimede loop with a moderate crystallization rate, and Figure 23 present an experiment on the Lyre loop with a high crystallization level. In other experiments, opposite behaviour is observed.

After the crystallization started, on both Archimede and Lyre loops, the mean chord length remains constant; which indicate that particles do not significantly agglomerate. After that, results obtained on both loops are similar, as the mean chord length increases. The flow on the Archimede loop stops because there is not enough available pressure induced by the gas lift, whereas the flow in the Lyre loop continues because of its Moineau pump.

Looking at the long term time evolution on the Lyre loop, one can see that the mean chord length significantly increases until a maximum value of $18 \mu \mathrm{m}$ and then decreases back to a lower average value $(\sim 12 \mu \mathrm{m})$. That can be attributed to the breaking of aggregates.

In order to better understand what happens during the first minutes after hydrate crystallization, Figure 24 provides a comparison between CLDs measured at four different instants between the beginning of the friction coefficient increase and the beginning of the mean chord length increase. All these distributions are square-weighted CLDs in order to 
emphasize the effect of hydrate particle agglomeration on the CLD, which are not detected on $L_{\text {mean. }}$

The CLD measured for the initial emulsion is quite narrow, with a mode around $5 \mu \mathrm{m}$ corresponding to the primary particles diameter constituting the aggregates and also to the remaining water droplets or free hydrate particles. After hydrate crystallization and agglomeration, the shape of the CLD becomes very different from the emulsion CLD. The peak corresponding to primary particles decreases of about $60 \%$. Hydrate particle agglomeration is evidenced through an increase of the spreading of the measured chord lengths until lengths of $100 \mu \mathrm{m}$, an increase in the proportion of chords measured between $50 \mu \mathrm{m}$ and $100 \mu \mathrm{m}$.

From Figure 24 it seems that the strong modification of the friction coefficient is actually linked to agglomeration effects even if the average value of the chord length remains unchanged.

For instants later than $105 \mathrm{~min}$, the number of agglomerates in the slurry is high enough to have an influence on the mean chord length, and its value keeps on increasing until $t=200 \mathrm{~min}$. Figure 25 presents four un-weighted CLDs measured at different instants of the Lyre loop test.

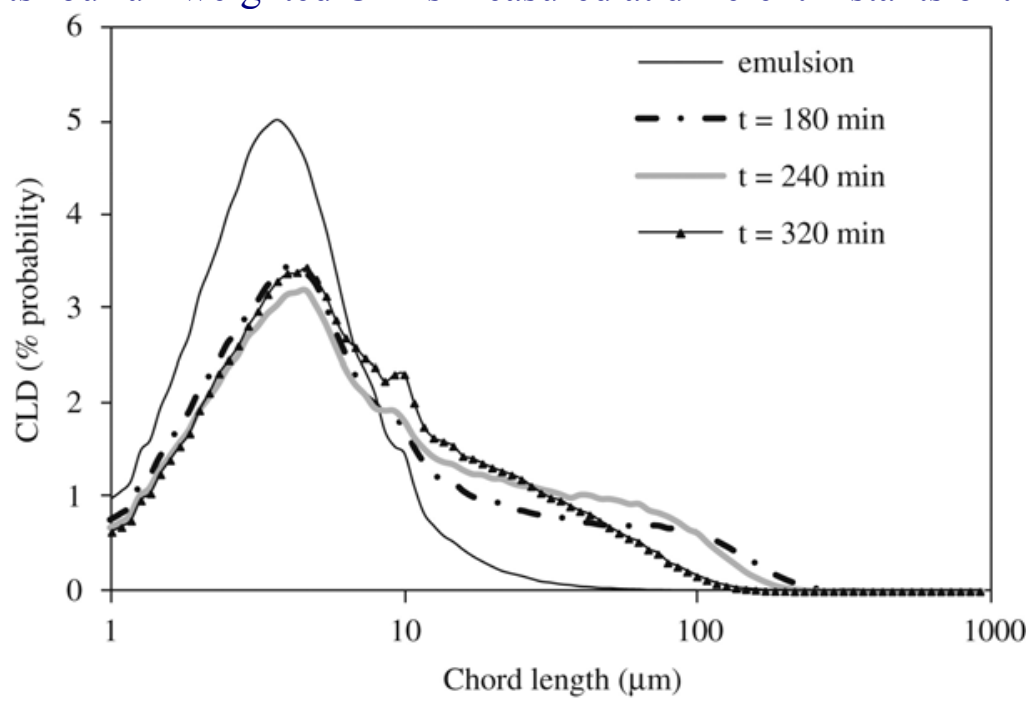

Figure 25: Comparison of un-weighted CLDs measured at different instants of the Lyre loop test (Lyre, $T=277 \mathrm{~K}, \mathrm{P}=7 \mathrm{MPa}$, 30\% vol. water, $0.5 \%$ add. (wt/wt water)).

The shape of the CLD for each time can be interpreted as follows:

* $t=86$ min: Emulsion CLD: presents a single mode distribution at $4 \mu \mathrm{m}$ which corresponds to the mean size of water droplets (primary particles size).

* $t=180$ min: Slurry CLD during the growth phase of agglomerates presents the mode corresponding to the primary particles diameter that is still predominant but its relative weight has decreased (35\%). Chords larger than $10 \mathrm{~m}(280 \mathrm{~m})$ appears corresponding to particles agglomeration.

* $t=240$ min: Slurry CLD during attrition phase of CLD agglomerates has the largest chord at $(210 \mu \mathrm{m})$.

* $t=320$ min: Slurry CLD at the end of attrition phase where the largest chord detected is smaller again $(140 \mu \mathrm{m})$.

Contrarily to the test presented before on the Archimede loop, during this test, a constant mean velocity was maintained, despite the pressure drop increase, preventing the plug of the pipe.

After agglomeration the highest chord lengths are obtained and after they decrease because shear becomes predominant. 
Another interesting observation is that for all CLDs measured during the test, the mode corresponding to the initial emulsion remains but its relative weight has decreased (approximately 35\%). Three different phenomena can justify this observation. The first one is that some water droplets or isolated hydrate particles keep the size of the primary particles and also in aggregates made up of these primary particles the probability of measuring a chord corresponding to the primary particle constituting the aggregate remains high (Turner et al., 2005) as illustrated in Figure 26.

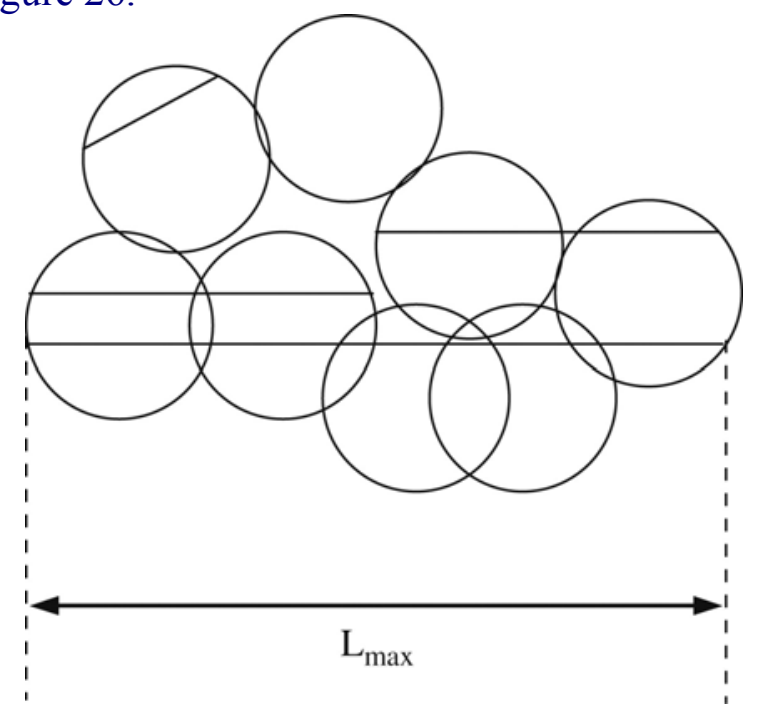

Figure 26: CLD measurement for an aggregate of spherical particles.

Lastly, agglomeration leads to a decrease of the number concentration of particles increasing the probability of measuring the largest chords of an aggregate.

\section{Comparison between simulation and experimental results}

In this section calculated results are compared with experiment. Remember that CLD are calculated from aggregates constructed by CCA with a given fractal dimension, number of particles and primary particles diameter.

From experiment the emulsion CLD has a single peak whose mode corresponds to the water droplets diameter that is considered the same of hydrates primary particles diameter. This diameter is measured to each experiment and used to calculate the CLD for each experiment in Part IV by fitting the number of primary particles and the fractal dimension.

The fractal dimension $\left(D_{f}\right)$ was initially set to 2.5 following the work of (Camargo and Palermo, 2002).

The criteria to fit calculated CLD with experiments CLD was the maximum chord length and the mean intensity of the shouldering corresponding to aggregates without taking into account all the secondary peaks.

This procedure was followed to calculate de CLD during crystallization in the Archimede flow loop.

In Figure 20 the mode of the main peak corresponding to the diameter of water droplets in the emulsion is located at $7 \mu \mathrm{m}$. So, the primary particles diameter is chosen equal to $7 \mu \mathrm{m}$ and with the fractal dimension $\left(D_{f}\right)$ equal to 2.5 as Camargo, the primary particles number was fitted equal to 50 in Figure 27 to CLD at $140 \mathrm{~min}$. 


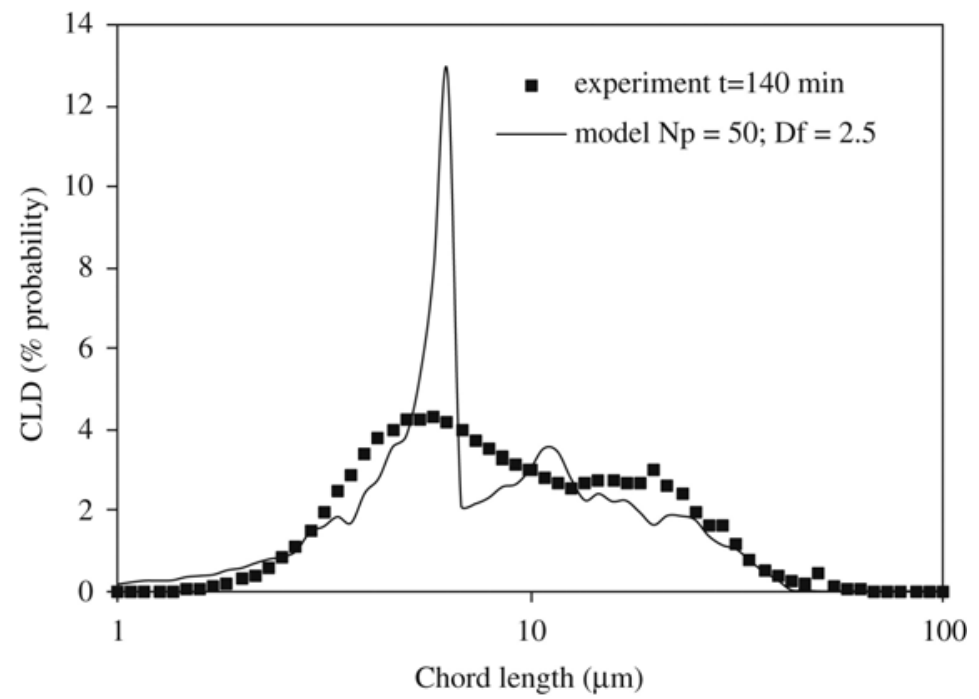

Figure 27: Simulated $C L D\left(N_{p}=50 ; D_{f}=2.5 ; k_{f}=1, D_{p}=7 \mu \mathrm{m}\right)$ and experimental $C L D$ ( $\left.t=140 \mathrm{~min}\right)$ (Archimede, $T=277 \mathrm{~K}, \mathrm{P}=7 \mathrm{MPa}$, $30 \%$ vol. water, $0.5 \%$ add. (wt/wt water)).

In Figures 28 and 29 the size interval of experimental CLD with an adjustable parameter $N_{p}$ is well described by the model, nevertheless the main peak has the same mode $(7 \mu \mathrm{m})$ their probability is different probably because aggregates are made from a monodispersed population and do not take into account a certain emulsion polydispersity.

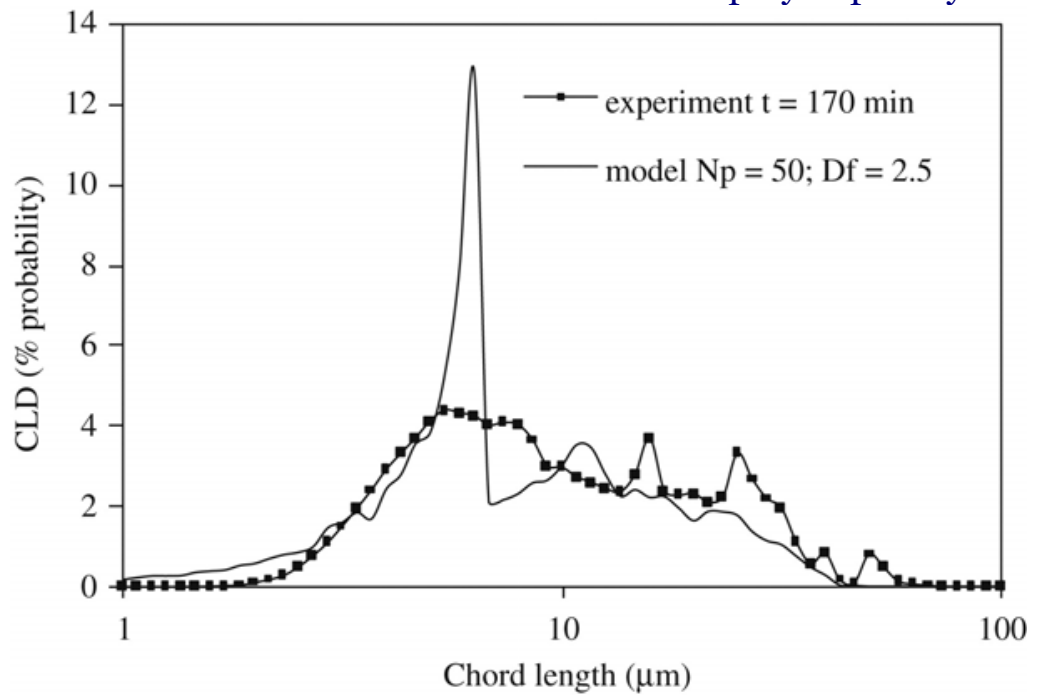

Figure 28: Simulated $C L D\left(N_{p}=50 ; D_{f}=2.5 ; k_{f}=1, D_{p}=7 \mu \mathrm{m}\right)$ and experimental $C L D(t=170 \mathrm{~min})$. (Archimede, $T=277 \mathrm{~K}, \mathrm{P}=7 \mathrm{MPa}$, 30\% vol. water, $0.5 \%$ add. (wt/wt water)).

The same procedure was followed for the experimental chord length distribution at $170 \mathrm{~min}$, and the results are shown in Figure 28.

Figure 29 shows that the same fractal dimension and the same number of primary particles used for modelling at 140 min give a chord length distribution which does not describe the peaks at larger chord lengths. The increase in the fractal dimension describes better these peaks, particularly around chord lengths of $30 \mu \mathrm{m}$. This proves that the fractal dimension allows taking into account the evolution of the aggregate compactness along a crystallization and agglomeration process under flow conditions.

The same procedure was used for experiments in Lyre flow loop. Figure 24 presents the CLD of the emulsion at $80 \mathrm{~min}$ with a main peak with a mode at $4 \mu \mathrm{m}$ corresponding to the water droplets in the emulsion. Consequently, the primary particles diameter chosen for the aggregate construction was $4 \mu \mathrm{m}$. The fractal dimension $\left(D_{f}\right)$ was arbitrarily set to 2.5 
following the work of (Camargo and Palermo, 2002). Once agglomerates have been constructed with CCA, CLD was calculated and fitted in with the experimental CLD by changing the number of primary particles in the agglomerate which plays a role on the maximum chord length obtained.

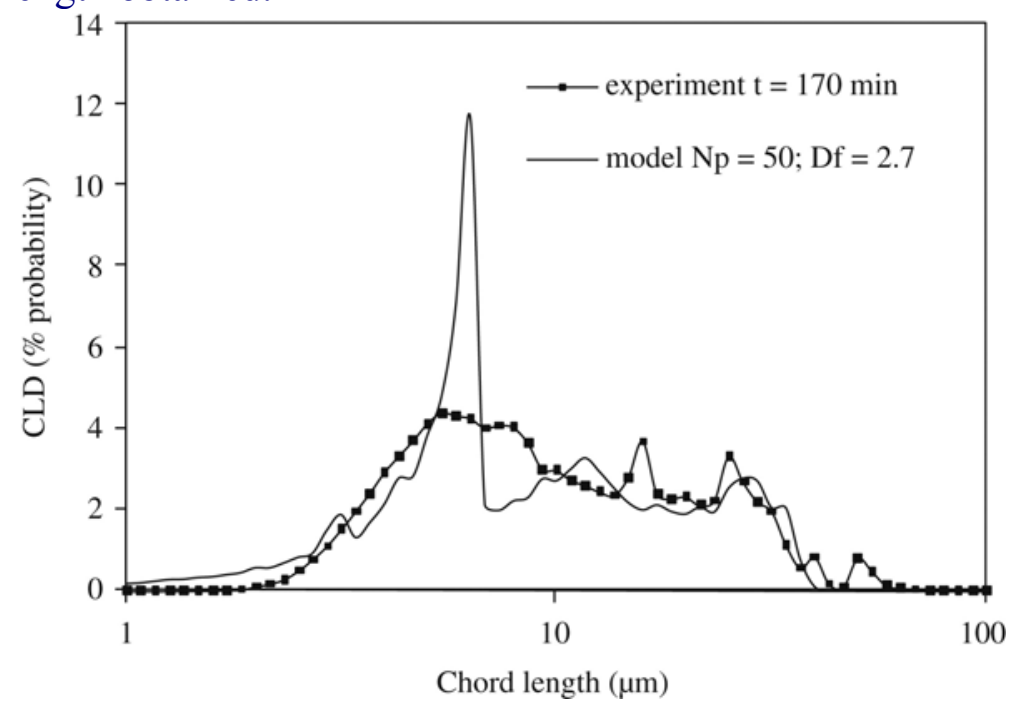

Figure 29: Simulated $C L D\left(N_{p}=50 ; D_{f}=2.7 ; k_{f}=1, D_{p}=7 \mu m\right)$ and experimental $C L D$ ( $\left.t=170 \mathrm{~min}\right)$. (Archimede, $T=277 \mathrm{~K}, \mathrm{P}=7 \mathrm{MPa}$, $30 \%$ vol. water, $0.5 \%$ add. (wt/wt water)).

Figure 30 shows the superposition between the experimental and the simulated CLD.

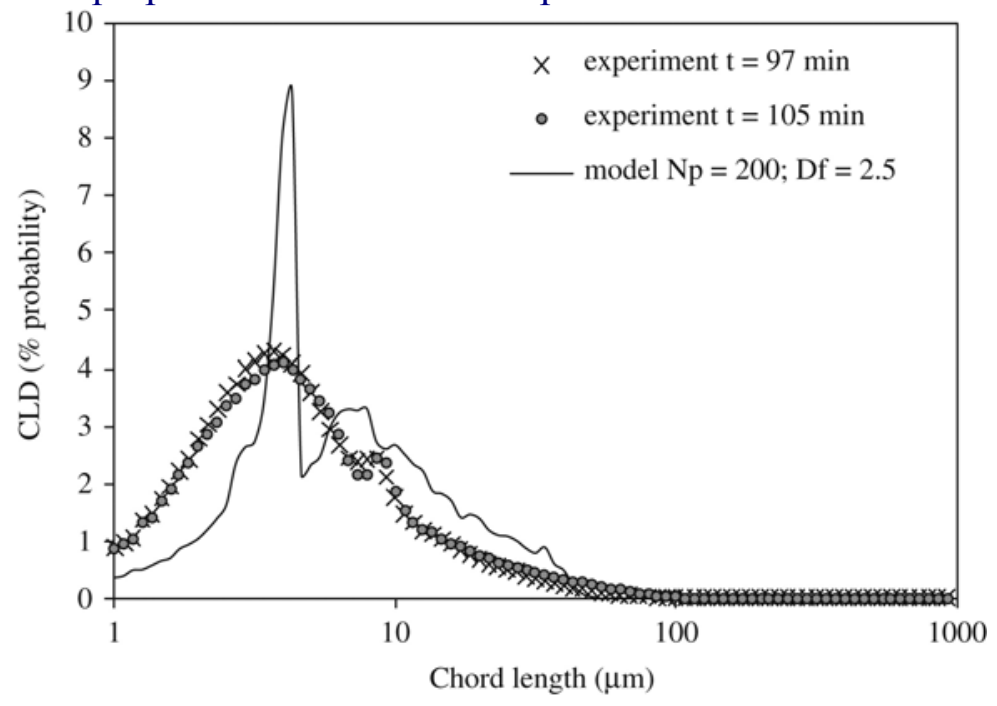

Figure 30: Simulated $C L D\left(N_{p}=200 ; D_{f}=2.5 ; k_{f}=1, D_{p}=4 \mu \mathrm{m}\right)$ and experimental $C L D$ (Lyre, $T=277 \mathrm{~K}$, $P=7 \mathrm{MPa}$, 30\%vol., $0,5 \% \mathrm{wt}$. add.) at $\mathrm{t}=97$ and $105 \mathrm{~min}$.

The simulated CLD was obtained for an aggregate with 200 primary particles. Both distributions have the same mode and the same chord lengths interval between 1 and $50 \mu \mathrm{m}$, but they do not have the same probability for each range of chord lengths because calculated CLD do not take into account the emulsion polydispersity. The same procedure is (Figures 32, 32 and 33) applied at different times of the crystallization and reported in Table 2.

Table 2. : Number of particles in simulated aggregate that give experimented CLD comparable to simulated $C L D\left(D_{p}=4 \mu m, k_{f}=1, D_{f}=2.5\right)$.

\begin{tabular}{llllll}
\hline$t$ (min) & 97 & 105 & 180 & 240 & 320 \\
$\mathrm{~N}_{\mathrm{p}}$ & 200 & 200 & 1500 & 1200 & 1000 \\
\hline
\end{tabular}

Lyre, T=277 K, P=7 MPa, 30\%vol. water, 0.5\% wt/water add. 


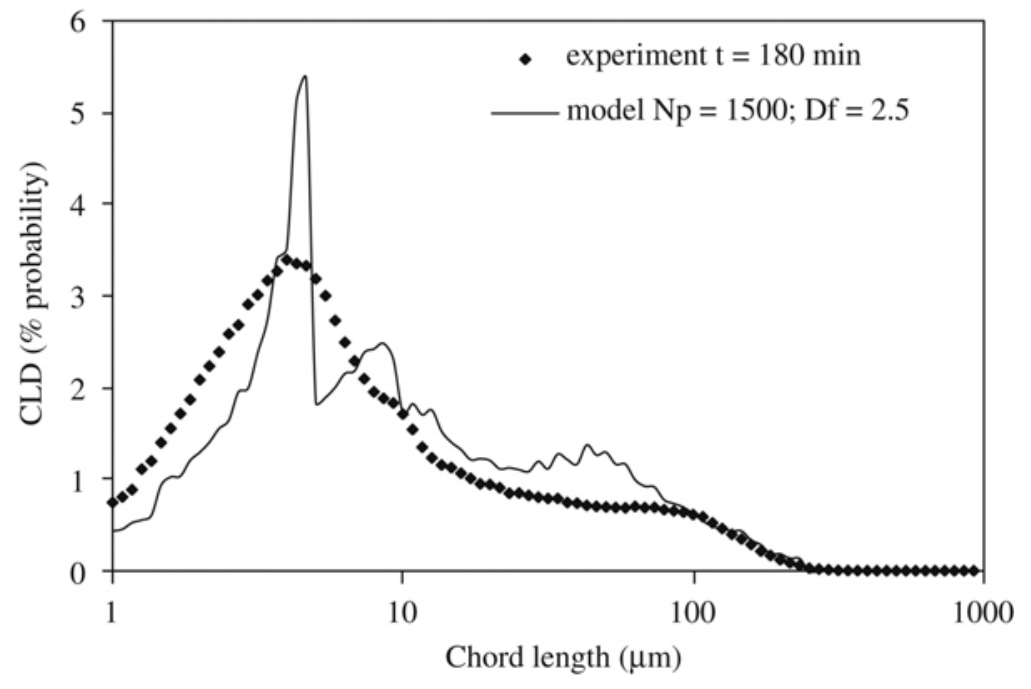

Figure 31: Simulated $C L D\left(N_{p}=1500 ; D_{f}=2.5 ; D_{p}=4 \mu \mathrm{m}\right)$ and experimental $C L D(t=180 \mathrm{~min})$.

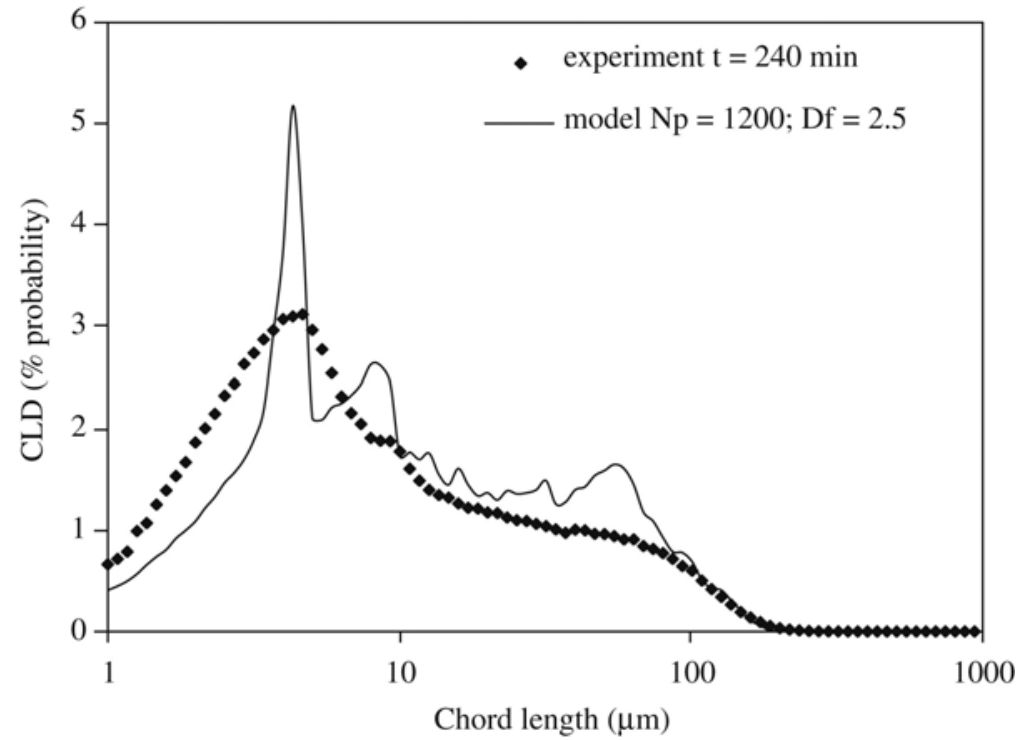

Figure 32: Simulated $C L D\left(N_{p}=1200 ; D_{f}=2.5 ; D_{p}=4 \mu \mathrm{m}\right)$ and experimental $C L D(t=240 \mathrm{~min})$.

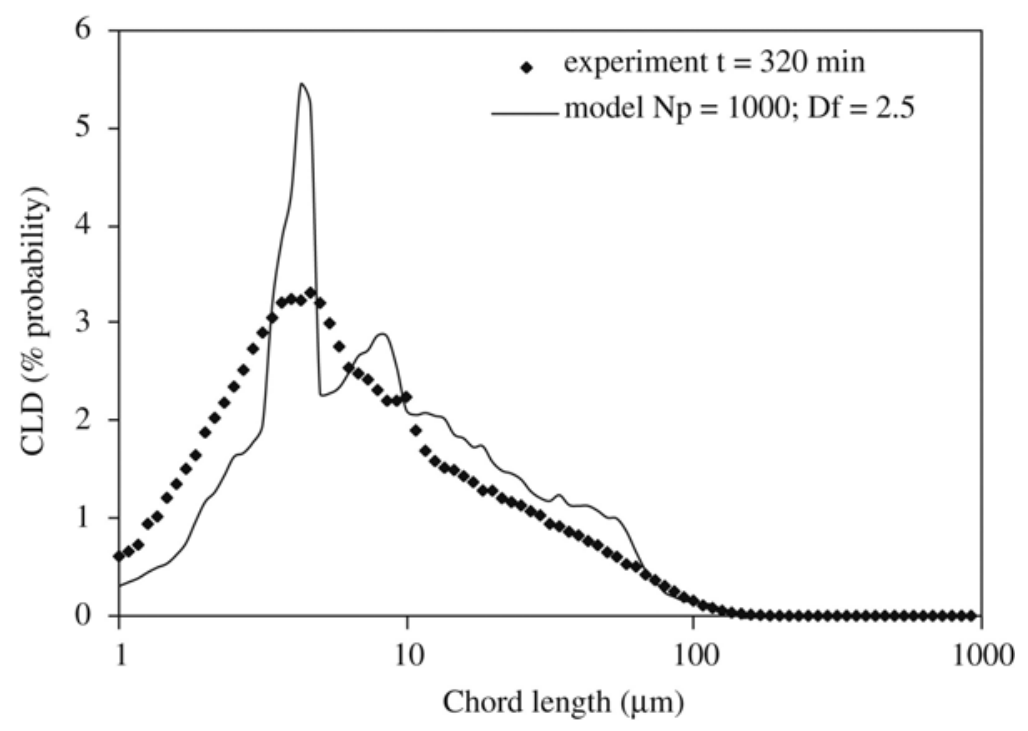

Figure 33: Simulated $C L D\left(N_{p}=1200 ; D_{f}=2.5 ; D_{p}=4 \mu \mathrm{m}\right)$ and experimental $C L D(t=240 \mathrm{~min})$. 
The fitted number of primary particles increases until $180 \mathrm{~min}$ and then decreases. This puts into evidence the formation of fractal aggregates until $180 \mathrm{~min}$. Then shear effects become predominant on agglomeration effects and aggregates tend to be eroded, and their size decreases (Camargo and Palermo, 2002). The comparison between simulated and experimental CLD is in Figures 31, 32 and 33.

In Figures 31, 32 and 33 calculated CLD are different from the experimental ones. The main difference concerns the smallest chord lengths and the amplitude of primary particles peak.

\section{Conclusions}

A study was carried out in order to model the CLD and assess the possibility of estimating the physical characteristics of gas hydrate aggregates circulating in a pressurized loop from measures with a FBRM probe. A new CCA algorithm was created and used to construct random aggregates characterized by their fractal dimension, the diameter of primary particles and their number of primary particles. The corresponding CLD distributions were then calculated and analysed.

The diameter of primary particles was found to be related to the sharp peak of the calculated chord length distributions corresponding to the mode of the peak obtained in the smallest detected chord lengths. The shape of the shoulder, located at larger chord lengths appeared to be indicative of the compactness of aggregate (characterised by its fractal dimension), and lastly, the maximum measured chord length is linked to the number of primary particles in each agglomerate.

The calculated CLDs from aggregated constructed from a monodispersed population of spheres were fitted to the experimental CLDs with a single fitted parameter: the number of primary particles. In a second time, it was shown that the fractal dimension can also be an interesting fitting parameter, if the compactness of the aggregates varies along an experiment. Further developments could be done in order to improve the agreement between the experimental and the calculated CLDs. As an example, using a polydispersed population from whose agglomerates will be built can be interesting to have a better agreement between the main peak of the CLD from model and experiments.

\section{Notations}

$D_{A} \quad$ equivalent diameter of an aggregate, $\mathrm{m}$

$D_{f i} \quad$ fractal dimension of an aggregate

$D_{\max } \quad$ maximal dimension of a particle, $\mathrm{m}$

$D_{p} \quad$ primary particle diameter, $\mathrm{m}$

$f \quad$ friction coefficient

$k_{f} \quad$ structure factor

$L_{\text {mean }} \quad$ un-weighted mean chord length, $\mu \mathrm{m}$

$L^{2}$ mean $\quad$ square-weighted mean chord length, $\mu \mathrm{m}$

$N \quad$ number of scans

$N_{p} \quad$ number of primary particles

$\mathrm{O}_{i} \quad$ centre of sphere

$O_{\text {o }} \quad$ centre of aggregate

$P \quad$ number of rotations

$\Delta P / L \quad$ linear pressure drop, $\mathrm{Pa} \mathrm{m}^{-1}$

$R_{e} \quad$ Reynolds number

$R_{g} \quad$ gyration radius, $\mathrm{m}$

$T$ time, $\min$

$u \quad$ mean velocity, $\mathrm{m} \mathrm{s}^{-1}$ 


\section{Acknowledgements}

The authors would like to thank Alain Lallemand and Fabien Chauvy at ENSM-SE for their precious technical help during the experiments performed on the Archimede flow loop as well as E. Peuriere and G. Avril who conducted all the tests on the Lyre pilot flow loop. The authors are really grateful for their technical expertise which widely contributes to the success of the experimental campaigns.

\section{References}

Bird, R.B., Stewart, W.E., Lightfoot, E.N., 1960. Transport Phenomena, Wiley, New York.

Camargo, R., Palermo, T., 2002. Rheological properties of hydrate suspensions in an asphaltenic cude oil. Proceedings of the $4^{\text {th }}$ International Conference on Gas Hydrates, Yokohama, Japan, May 19-23.

Clarke, M.A., Bishnoi, P.R., 2004. Determination of the intrinsic rate constant and activation energy using in-situ particle size analysis. Chemical Engineering Science 59, 2983-2993.

Clarke, M.A., Bishnoi, P.R., 2005. Determination of the intrinsic kinetics of $\mathrm{CO} 2$ gas hydrates formation using in-situ particle size analysis. Chemical Engineering Science 60, 695-709.

Filippov, V., Zurita, M., Rosner, D.E., 2000. Fractal-like Aggregates: Relation between Morphology and Physical Properties. Journal of Colloid and Interface Science 229, 261273.

Fidel-Dufour, A., Gruy, F., Herri, J.M., 2006. Rheology of methane hydrate slurries during their crystallization in a water in dodecane emulsion under flowing. Chemical Engineering Science 61, 505-515.

Greaves D., Boxall J., Mulligan J., Sloan E. D., Koh C., 2008. Hydrate formation from high wtare content-crude oil emulsions. Chemical Engineering Science 63, 5410-5419.

Jullien, R., Botet, R., 1987. Aggregation and fractal aggregates. World Scientific, Singapore.

Heath, A.R., Fawell, P.D., Bahri, P.A., Swift, J.D., 2002. Estimating average particle size by focused beam reflectance measurement FBRM. Particle \& Particle Systems Characterization 19, 84-95.

Langston, P.A., 2002. Comparison of least-squares method and Bayes' theorem for deconvolution of mixture composition. Chemical Engineering Science 57, 2371-2379.

Langston, P.A., Jones, T.F., 2001. Non-spherical 2-dimensional particle size analysis from chord measurements using Bayes' theorem. Particle and Particle Systems Characterization $18,12-21$.

Leba, H., 2006. Utilization of FBRM in the Control of CLD in a Batch Cooled Crystallizer. Master report.

Lee, D., Bonner, J.S., Garton, L.S., Ernest, A.N.S., and Autenrieth, R.L., 2000. Modeling coagulation kinetics incorporating fractal theories: a fractal rectilinear approach. Water Research, 34, 1987-2000.

Li, M., Wilkinson, D., 2005. Determination of non-spherical particle size distribution from chord length measurements. Part 1: Theoretical analysis. Chemical Engineering Science $60,3251-3265$.

Liu, W., Clark, N.N., 1995. Relationships between distributions of chord lengths and distributions of bubble sizes including their statistical parameters. International Journal of Multiphase Flow 21, 1073-1089.

Liu,W., Clark, N.N., Karamavruc, A.I., 1997. Relationship between bubble size distributions and chord-length distribution in heterogeneously bubbling systems. Chemical Engineering Science 53, 1267-1276.

Mackowski, D.W., 1995. Appl. Opt. 343535.

Mettler-Toledo Lasentec $\AA$ Product Group, 2001. Lasentec $\AA$ D6oo Hardware Manual. Mettler-Toledo AutoChem, Inc., Redmond, WA.

Mills, P., 1985. Non-Newtonian behaviour of flocculated suspensions. Journal de Physique Lettres 46, 301-309. 
Panchard, V., Darbouret, M., Palermo, T., Peytavy, J.L., 2007. Gas hydrates slurry flow in a black oil. Prediction of gas hydrates particles agglomeration and linear pressure drop. Proceedings of the $13^{\text {th }}$ International Conference of Multiphase Production Technology, Edinburgh, UK, pp. 343-355.

Potanin, A.A., 1991. On the mechanism of aggregation in the shear flow of suspension. Journal of Colloid and Interface Science, vol 145, 140-157.

Richmond, W.R., Jones, R.L., Fawell, P.D., 1998. The relationship between particle aggregation and rheology in mixed silica-titania suspensions. Chemical Engineering Journal 71, 67-75.

Ruf, A., Worlitschek, J., Mazzotti, M., 2000. Modelling and Experimental Analysis of PSD Measurements through FBRM. Particle and Particle. Systems Characterization 17, 167179.

Simmons, M.J.H., Langston, P.A., Burbidge, A.S., 1999. Particle and droplet size analysis from chord distributions. Powder Technology 102, 75-83.

Sloan, E.D., 1998. Clathrate hydrates of natural gases. Second ed., Marcel Dekker, Inc, New York.

Tadayyon, A., Rohani, B., 1998. Determination of particle size distribution by Par-Tec $®$ 100: Modeling and experimental results. Particle and Particle Systems Characterization 15, 127-135.

Thouy, R., and Jullien, R., 1994. J. Phys. A: Math. Gen. 27, 2953.

Turner, D.J., Kleehammer, D.M., Miller, K.T., Koh, C.A., Sloan, E.D., 2005. Formation of hydrate obstructions in pipelines: Hydrate particle development and slurry flow. Proceedings of the $5^{\text {th }}$ International Conference on Gas Hydrates, Trondheim, Norway, June 13-16, pp. 1116-1125.

Worlitschek, J., 2003. Monitoring, modelling and optimization of batch cooling crystallization. PhD thesis of Swiss Federal Institute of technology, Zürich.

Wynn, E.J.W., 2003. Relationship between particle-size and chord-length distributions in focused beam reflectance measurement: stability of direct inversion and weighting. Powder Technology 133, 125-133. 